\title{
Assessment of vulnerability zones for ground water pollution using GIS-DRASTIC-EC model: A field-based approach
}

\author{
D Anantha RaO ${ }^{1, *}$, Pradeep K NaIK ${ }^{1}$, Sunil K Jain ${ }^{1}$, \\ K Vinod Kumar ${ }^{2}$ and E N DHANAMJaya RaO ${ }^{3}$ \\ ${ }^{1}$ Central Ground Water Board, North Western Region, Ministry of Water Resources, River Development and \\ Ganga Rejuvenation, Government of India, Chandigarh, India. \\ ${ }^{2}$ Geosciences Group, National Remote Sensing Centre, Balanagar, Hyderabad, India. \\ ${ }^{3}$ Department of Geology, Andhra University, Visakhapatnam, Andhra Pradesh, India. \\ *Corresponding author.e-mail: ananthcgwb@gmail.com
}

MS received 3 May 2017; revised 22 August 2017; accepted 2 September 2017; published online 22 May 2018

Assessment of groundwater vulnerability to pollution is an essential pre-requisite for better planning of an area. We present the groundwater vulnerability assessment in parts of the Yamuna Nagar District, Haryana State, India in an area of about $800 \mathrm{~km}^{2}$, considered to be a freshwater zone in the foothills of the Siwalik Hill Ranges. Such areas in the Lower Himalayas form good groundwater recharge zones, and should always be free from contamination. But, the administration has been trying to promote industrialization along these foothill zones without actually assessing the environmental consequences such activities may invite in the future. GIS-DRASTIC model has been used with field based data inputs for studying the vulnerability assessment. But, we find that inclusion electrical conductivity (EC) as a model parameter makes it more robust. Therefore, we rename it as GIS-DRASTIC-EC model. The model identifies three vulnerability zones such as low, moderate and high with an areal extent of 5\%,80\% and $15 \%$, respectively. On the basis of major chemical parameters alone, the groundwater in the foothill zones apparently looks safe, but analysis with the help of GIS-DRASTIC-EC model gives a better perspective of the groundwater quality in terms of identifying the vulnerable areas.

Keywords. Groundwater pollution; chemical quality; aquifer vulnerability; GIS-DRASTIC model; Indo-Gangetic Plains.

\section{Introduction}

Groundwater contamination, especially of the unconfined aquifers, is one of the serious environmental problems in the world today. Once polluted, remediation of the aquifers becomes extremely difficult, and sometimes it becomes almost impossible to restore their original quality (Qinghai et al. 2007; Umar et al. 2009). Therefore, groundwater vulnerability assessment is an important process to understand about an area, especially for planners and decision makers (Gogu and Dassarguess 2000; Vias et al. 2005; Qinghai et al. 2007). It confirms if the water resources of an area are under stress and identify critical areas for maintenance of the groundwater quality. Such studies, therefore, provide valuable information to stakeholders working on prevention of further deterioration 
of environmental quality (Mendoza and Barmen 2006).

The foothill zones of the Himalayas locally called the 'Terai' belt in north-western India in the IndoGangetic Plains, are the freshwater zones in India that serve as recharge areas for the regions in the south. There are at least 10 Indian states that encompass these foothill zones across the Himalayas. The administration has been trying to promote industrialization along these foothill zones not only to offer employment opportunities to the people of the hilly tracts, but also to enable them to become a part of the mainstream activities of the country. But, numerous side effects of such industrialization have cropped up in recent years; there are reports of groundwater contamination in many pockets, such as Nalagarh area in Himachal Pradesh (Herojeet et al. 2016; Kamaldeep et al. 2011) and Dehradun, Kashipur and Udham Singh Nagar areas in Uttarakhand (CPCB 2013). The present study aims at vulnerability assessment of groundwater contamination in one such area in the Yamuna Nagar District of the State of Haryana, India (figure 1). The paper examines if the decisions of the administration to industrialize the foothill zones are correct and suggests options as to how to keep these zones safe from groundwater contamination.

DRASTIC model, proposed by Aller et al. (1987), has been used for the vulnerability assessment in this study. A number of vulnerability studies using DRASTIC model have been carried out in the Indo-Gangetic Plains in the recent past (Chakraborty and Sikdar 2007; Rahman 2008; Umar et al. 2009; Khan et al. 2010; Alam et al. 2012; Saha and Alam 2014; Singh et al. 2015). Chakraborty and Sikdar 2007 used DRASTIC model for assessment of aquifer vulnerability to arsenic pollution in West Bengal. But, the area chosen was already known for arsenic contamination. Their work mainly carried out sensitivity assessment with the help of DRASTIC model aided by statistical analysis. Rahman (2008) used DRASTIC-GIS model to evaluate the groundwater vulnerability zones around Aligarh city covering an area of about $40 \mathrm{~km}^{2}$. This work is very useful to beginners for proper usage of the model, but it considers a two-dimensional disposition of geology without proper explanation of the lateral and vertical variations of the hydro-geological

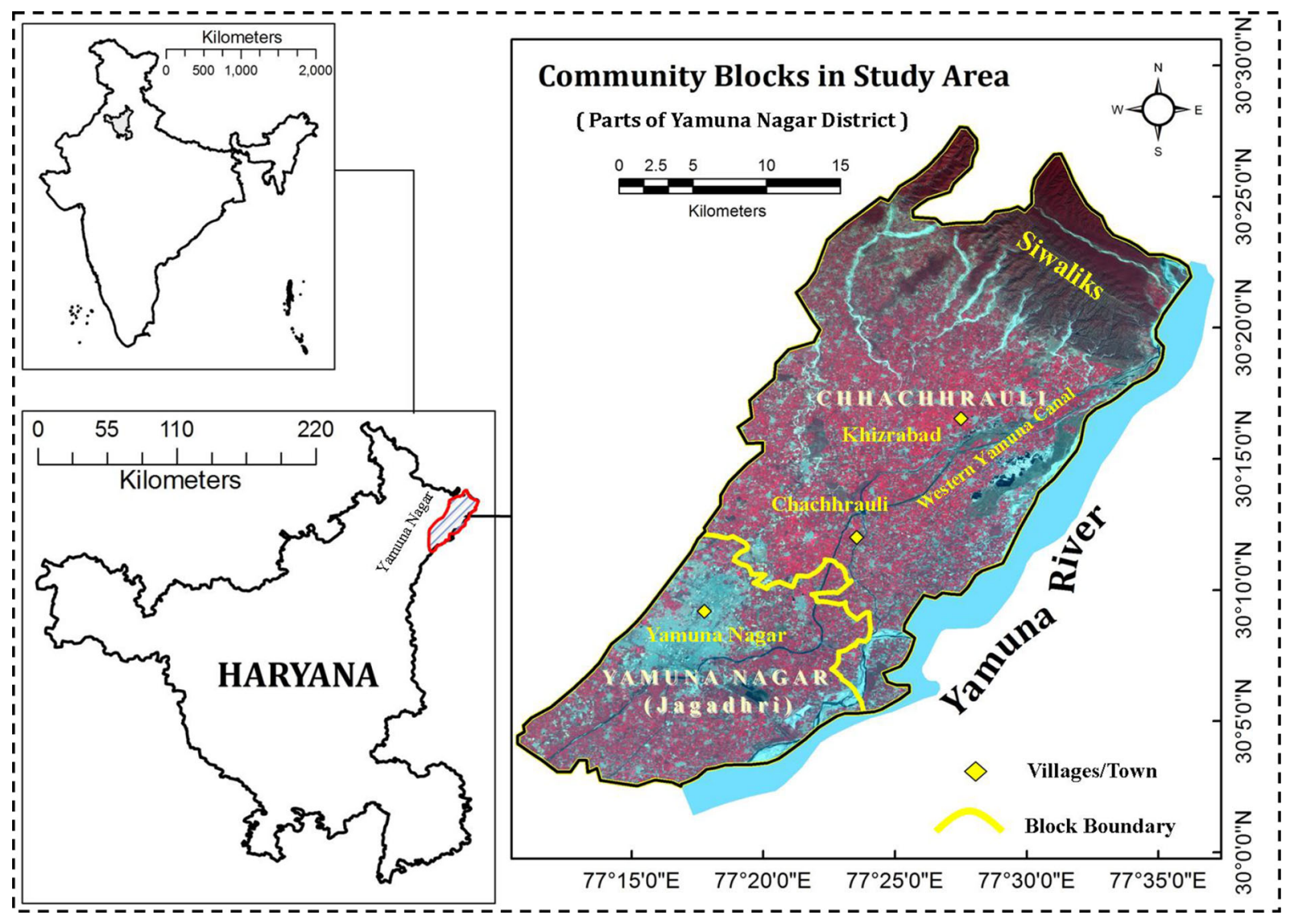

Figure 1. Location of the upper Yamuna River basin, Yamuna Nagar District, Haryana State, India. 


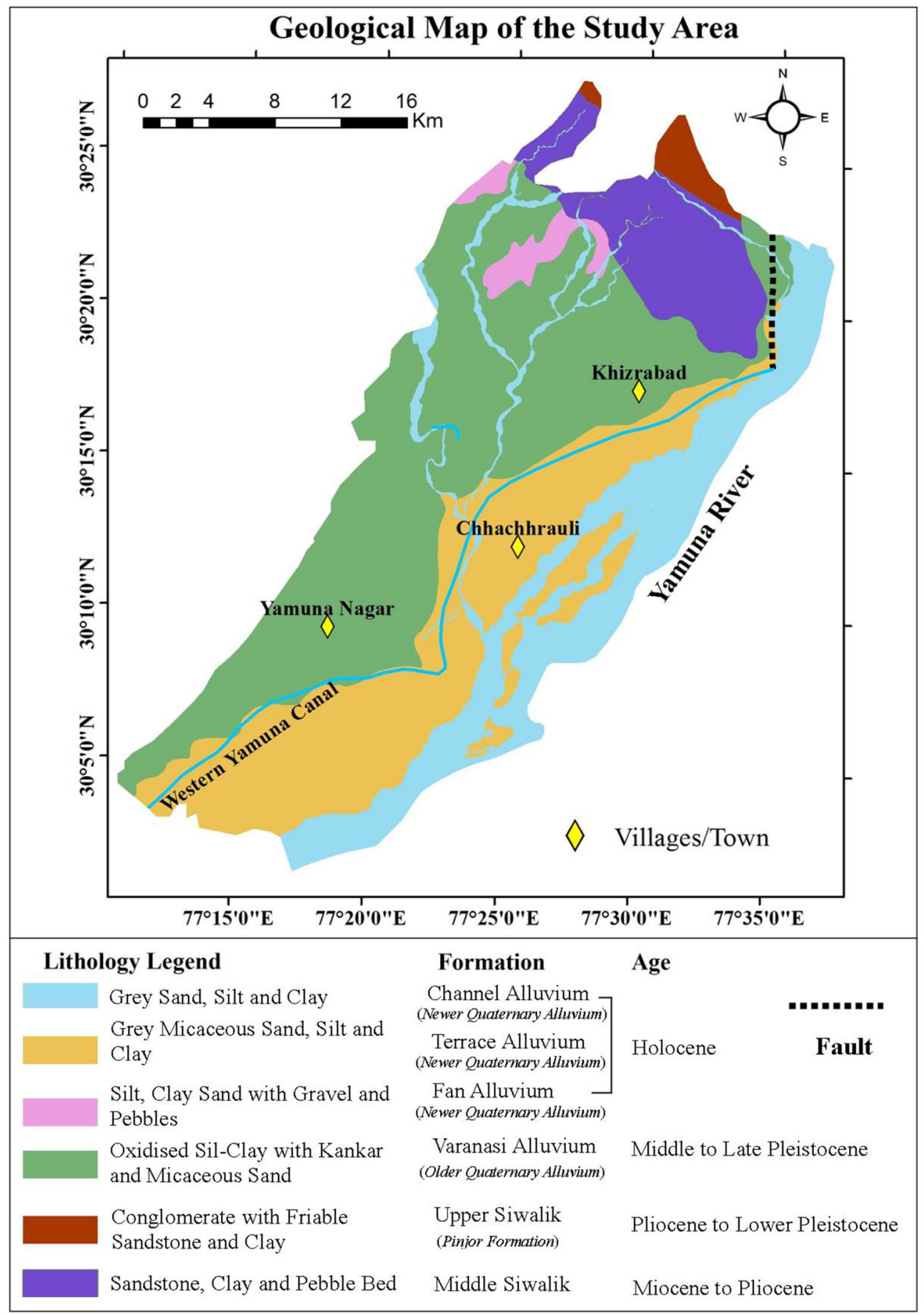

Figure 2. Geology of the upper Yamuna River basin in Yamuna Nagar District, Haryana State, India.

framework. Information about the impact of vadose zone is obtained through geophysical means without proper validation with the drilled data.

Umar et al. (2009) mapped groundwater vulnerable zones of an alluvial aquifer in parts of the central Ganga Plain in western Uttar Pradesh covering an area of about $1060 \mathrm{~km}^{2}$ using land use and DRASTIC model. Soil was assumed to be loam and sandy loam type for the entire study area, and standard weight and rating were considered. Topography was not at all considered since it was assumed that its contribution to pollution was minimal. Land use was considered as the major contributing parameter and was assigned the maximum weight of 5 . The model was validated mainly with the total dissolved solids (TDS) and 


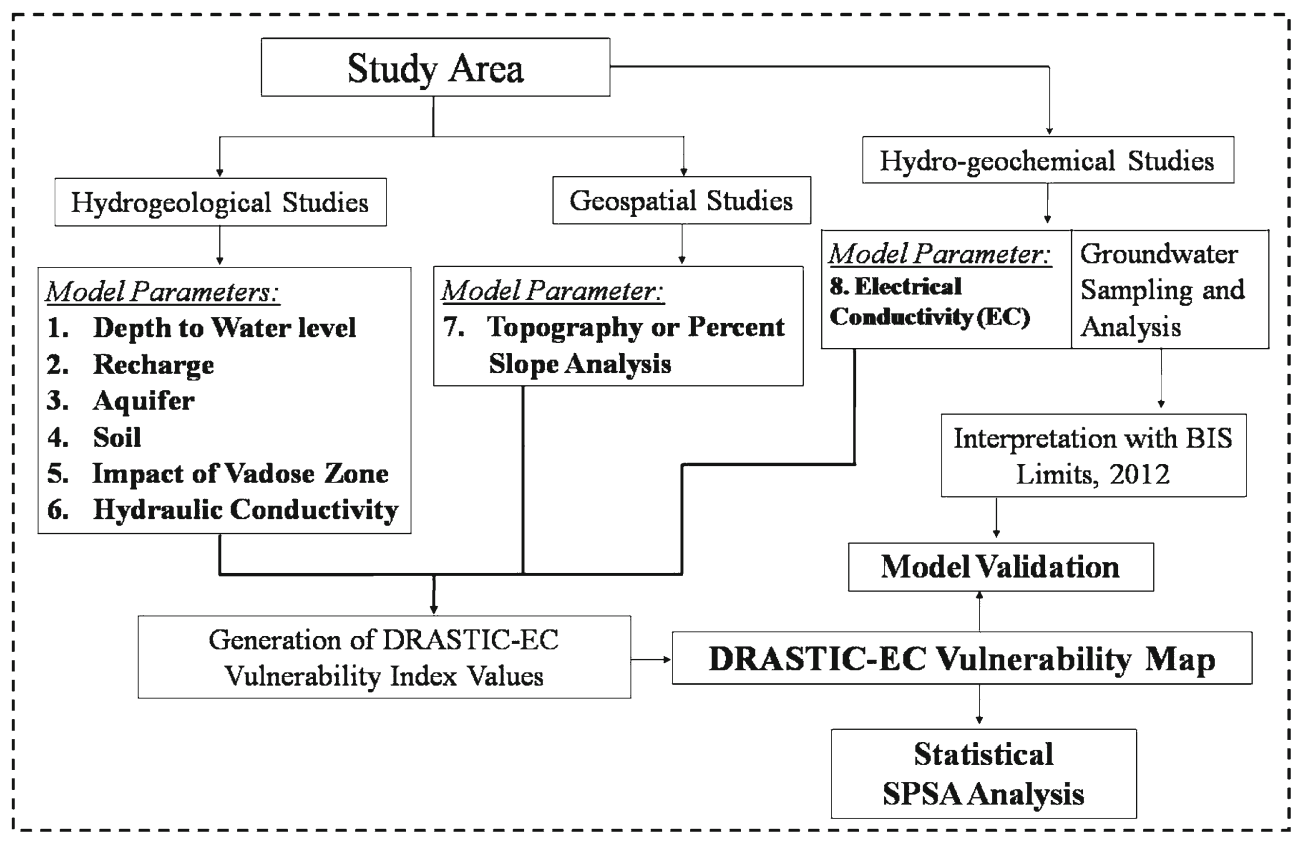

Chart 1. The flowchart of the methodology adopted for this study.

electrical conductivity (EC); heavy metals were not considered. Khan et al. (2010) assessed vulnerability zones in an area of about $650 \mathrm{~km}^{2}$ in the Indo-Gangetic Plains, but the methods used were simply a copy of Umar et al. (2009) with similar limitations. Although land use was considered as the main contributing parameter for groundwater vulnerability, it lacked a land use map. Alam et al. (2012) used the similar procedure as those of Umar et al. (2009) and Khan et al. (2010) and had the similar limitations, but with the better explanation of the aquifer disposition. They termed their method as DRASTICLU.

Saha and Alam (2014) attempted to assess groundwater vulnerability using DRASTIC, Pesticide DRASTIC and Pesticide DRASTIC-LU models in Nalanda district of Bihar state covering an area of $2200 \mathrm{~km}^{2}$. But, this work does not properly explain the lateral and vertical variations of the aquifer disposition. Validation of the model is carried out by nitrate concentrations. Singh et al. (2015) assessed the groundwater vulnerability around Lucknow city area using a modified DRASTIC model called DRASTICA with the last letter standing for 'anthropogenic'. They used satellite observations of nightlights from human settlements as a proxy for land use/land cover. For depth to groundwater levels, only nine wells monitored by CGWB were used for an area of about $2500 \mathrm{~km}^{2}$ with a well density of one well per $278 \mathrm{~km}^{2}$, which is technically very sparse for the purpose of pollution assessment. For the entire $2500 \mathrm{~km}^{2}$ of area, conductivity value is taken as $>10 \mathrm{~m} /$ day which may not possibly be true for all areas even in alluvium. Validation is done by nitrate concentrations only; heavy metals were not considered.

All the above studies have been based on external data sources and some of them are city centric. They all deal with the middle IndoGangetic Plains where groundwater pollution is evident (CPCB 2013). The present study, on the other hand, is a purely field-based approach with all data generated in the field itself by the first author himself. Moreover, it deals with foothill zones of the Siwalik Hill Ranges considered to be fresh water zones due to their physiographic locations. Major chemical parameters affirm these zones as safe areas, but GIS-DRASTIC model proves them otherwise. This paper discusses this context at length.

Conventionally, the nomenclature of DRASTIC includes seven parameters, such as Depth to water, net Recharge, Aquifer media, Soil media, Topography, Impact of vadose zone and Hydraulic Conductivity to form the acronym, DRASTIC. Except topography, six other parameters are hydrogeological by nature, but chemical component is missing in the model. To give a chemical 
Table 1. Assigned ratings and weights of DRASTIC parameters.

\begin{tabular}{|c|c|c|c|c|}
\hline Parameters & $\begin{array}{l}\text { Total scale } \\
\qquad(\mathrm{R})\end{array}$ & $\begin{array}{l}\text { Weight } \\
\text { scale }(W)\end{array}$ & $\begin{array}{l}\text { Rating scale } \\
(\mathrm{R}) \text { ranges }\end{array}$ & References \\
\hline Depth to water level (D) & 7,9 and 10 & 5 & $\begin{array}{l}<5 \mathrm{~m} \mathrm{bgl}=10,5-10 \mathrm{~m} \mathrm{bgl}=9, \\
\quad \text { and }>15 \mathrm{~m} \mathrm{bgl}=7\end{array}$ & Rahman (2008) \\
\hline Net recharge $(\mathrm{R})$ & 9 & 4 & Net recharge $>254 \mathrm{~mm}=9$ & Aller et al. (1987) \\
\hline Aquifer media (A) & 8 & 3 & $\begin{array}{l}\text { Sand and gravelly/sandy aquifer } \\
\text { (6-9 rating })=8\end{array}$ & $\begin{array}{l}\text { Aller et al. (1987), } \\
\text { Rahman (2008) }\end{array}$ \\
\hline Soil media $(\mathrm{S})$ & $1,5,6$ and 9 & 2 & $\begin{array}{l}\text { Non-aggregated clay }=1, \text { loam }=5, \\
\text { sandy loam }=6 \text { and sand }=9\end{array}$ & Aller et al. (1987) \\
\hline Topography $(\mathrm{T})$ & 5 and 9 & 1 & $\begin{array}{l}\% \text { slope of } 2-6=9 \\
\% \text { slope of } 6-12=5\end{array}$ & Aller et al. (1987) \\
\hline Impact of vadose zone (I) & $1,2,5$ and 6 & 5 & $\begin{array}{l}\text { Silt and clay }=1 \text { and } 2, \text { sand, } \\
\text { gravel with significant silt }=5 \text { and } \\
\text { sand, gravel with significant clay }=6\end{array}$ & Aller et al. (1987) \\
\hline Hydraulic conductivity (C) & 2 and 4 & 3 & $5-10 \mathrm{~m} /$ day $=2$ & $\begin{array}{l}\text { Qinghai et al. } \\
\text { (2007) }\end{array}$ \\
\hline Electrical conductivity (EC) & 5 and 7 & 5 & $\begin{array}{l}10-15 \mathrm{~m} / \text { day }=4 \\
\mathrm{EC}<500 \mu \mathrm{S} / \mathrm{cm}=5, \\
\mathrm{EC} 500-1000 \mu \mathrm{S} / \mathrm{cm}=7, \\
\mathrm{EC} 1000-1500, \mathrm{EC}=9, \text { and } \\
\mathrm{EC}>1500=10\end{array}$ & This work \\
\hline
\end{tabular}

dimension to the model, electrical conductivity (EC) is added as the eighth parameter to form the acronym DRASTIC-EC for ease of reference.

\section{Study area}

The study area is a part of the upper Yamuna sub-basin of the Indo-Gangetic Plains and lies between the North latitudes $30^{\circ} 2^{\prime} 30^{\prime \prime}$ and $30^{\circ} 27^{\prime} 40^{\prime \prime}$ and East longitudes $77^{\circ} 10^{\prime} 40^{\prime \prime}$ and $77^{\circ} 36^{\prime} 15^{\prime \prime}$ in parts of Chhachhrauli and Jagadhri administrative blocks of Yamuna Nagar District south of the Siwalik Hill ranges covering an area of about $800 \mathrm{~km}^{2}$ (figure 1). The climate of the area is sub-tropical (CoI 2011) with the average normal rainfall of about $921 \mathrm{~mm}$ during the last decade. The digital elevation model (DEM) exhibits a gentle slope from north to south, and the ground elevation ranges from 611 to $196 \mathrm{~m}$ above the mean sea level (Bhuvan Archive data-Cartosat DEM, NRSC-ISRO 2008). The land use classes are built-up areas (15\%), agricultural land $(55 \%)$, forest land (15\%) and water bodies and barren land/wasteland (15\%) (Bhuvan thematic data-LULC-2011-12, NRSC-ISRO 2012).

The soils are mostly sandy, sandy loam, loamy, and clayey-loam types (NBSS and LUP 1994). About $80 \%$ of the study area is covered with fluvial geomorphic units/landforms such as piedmont alluvial plain, active alluvial plain, older alluvial plain, older floodplain, etc., of level-2 classification (scheme developed by NRSC-GSI 2010). Other landform units include alluvial fans, oxbow lakes, point bars, braided bars, channel bars, valley fills, paleochannels, terraces, abandoned channels, meanders, etc. These landforms contain abundant groundwater resources. The major geological formations are primarily the older and newer Quaternary alluvium of the Yamuna River terraces of the Middle Pleistocene to Holocene Age (Verma 1976; Kumar and Das 2007) and Upper and Middle Siwalik formations consisting of sandstone, claystone, pebble bed and conglomerates of Miocene to Lower Pleistocene Age. The active Himalayan thrust fault, known as the Main Boundary Thrust (MBT) fault, exists in the north-eastern part (figure 2). The Yamuna River flows along this strike-slip fault. Yamuna Nagar District is the industrial hub of Haryana State (MSME-DI 2012), 

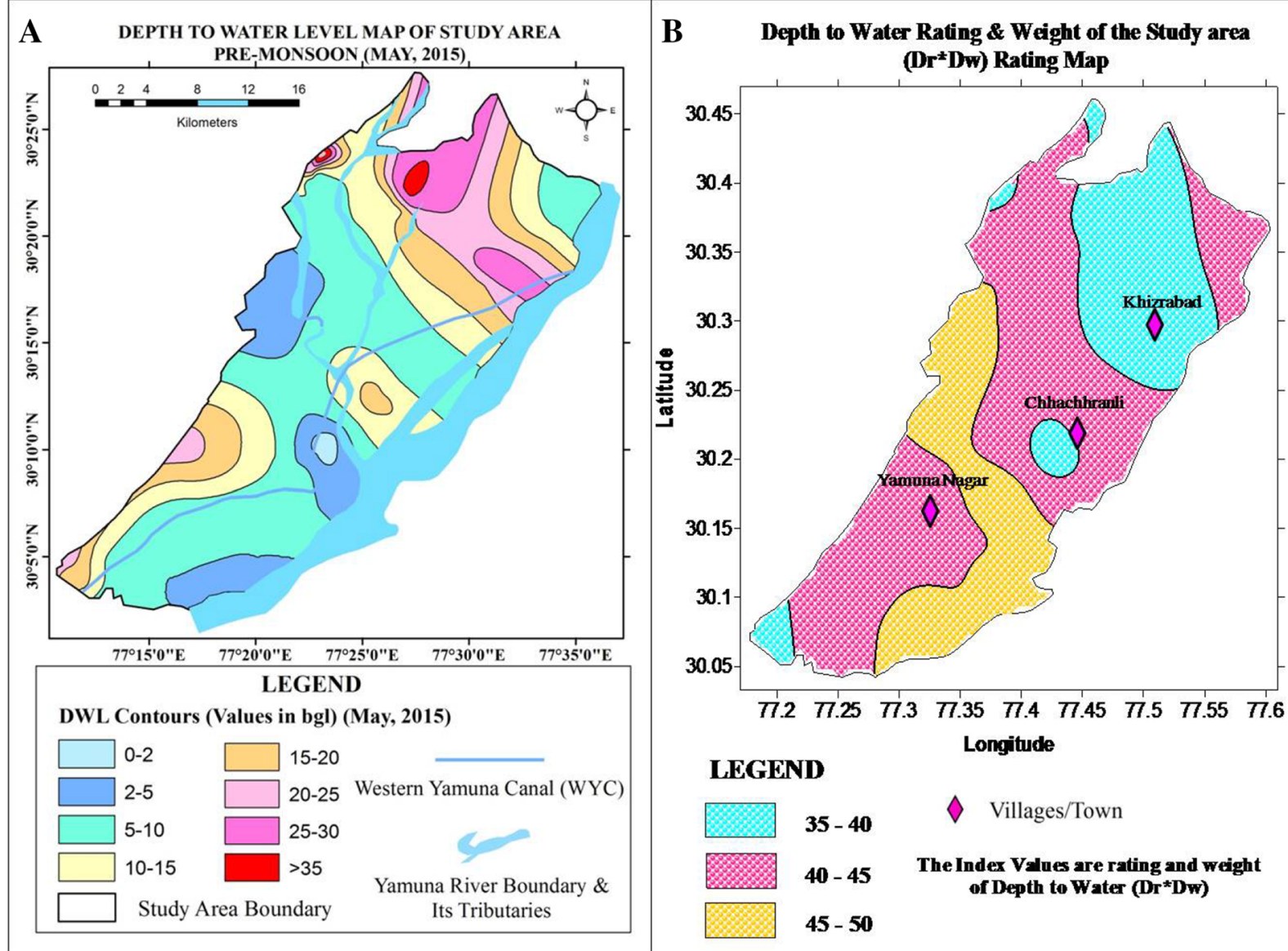

Figure 3. (a) Depth to ground water level map of the study area during May 2015. (b) Index map showing depth to water level (D) in the study area.

Table 2. Net recharge calculation in the study area (after CGWB 2011).

\begin{tabular}{llc}
\hline State & \multicolumn{2}{c}{$\begin{array}{c}\text { Haryana (India) } \\
\text { Yamuna Nagar }\end{array}$} \\
\cline { 2 - 3 } Administrative block & Chhachhrauli & Jagadhri \\
\hline Total area (hectare metre: ham) & 531,55 & 27,270 \\
Area suitable for ground water recharge (ham) & 399,55 & 27,270 \\
Recharge from rainfall in monsoon season & $140.45 \mathrm{~mm}$ & $170.54 \mathrm{~mm}$ \\
Recharge from rainfall in non-monsoon season & $61.60 \mathrm{~mm}$ & $56.10 \mathrm{~mm}$ \\
Recharge from other sources & & \\
Recharge from other sources in monsoon season & $76.11 \mathrm{~mm}$ & $44.55 \mathrm{~mm}$ \\
Recharge from other sources non-monsoon season & $74.98 \mathrm{~mm}$ & $32.58 \mathrm{~mm}$ \\
Annual ground water recharge (mm) & $353.14 \mathrm{~mm}$ & $303.77 \mathrm{~mm}$ \\
\hline
\end{tabular}

and with further expansion of industries, there is a rapid growth of urbanization in the district including the study area.

\section{Methodology and data collection}

A flow chart of the methodology adopted for this study has been shown in Chart 1. Ground water is the major contributor for agriculture, industrial and domestic uses in the study area. The shallow aquifers, which is mostly unconfined, is prone to contamination by various sources. Therefore, ground water vulnerability has been assessed for shallow aquifer only using GIS-DRASTIC model (Aller et al. 1987) with addition of EC as a model parameter to give a chemical dimension to the model. The modified model has been named as GIS-DRASTIC-EC model. 


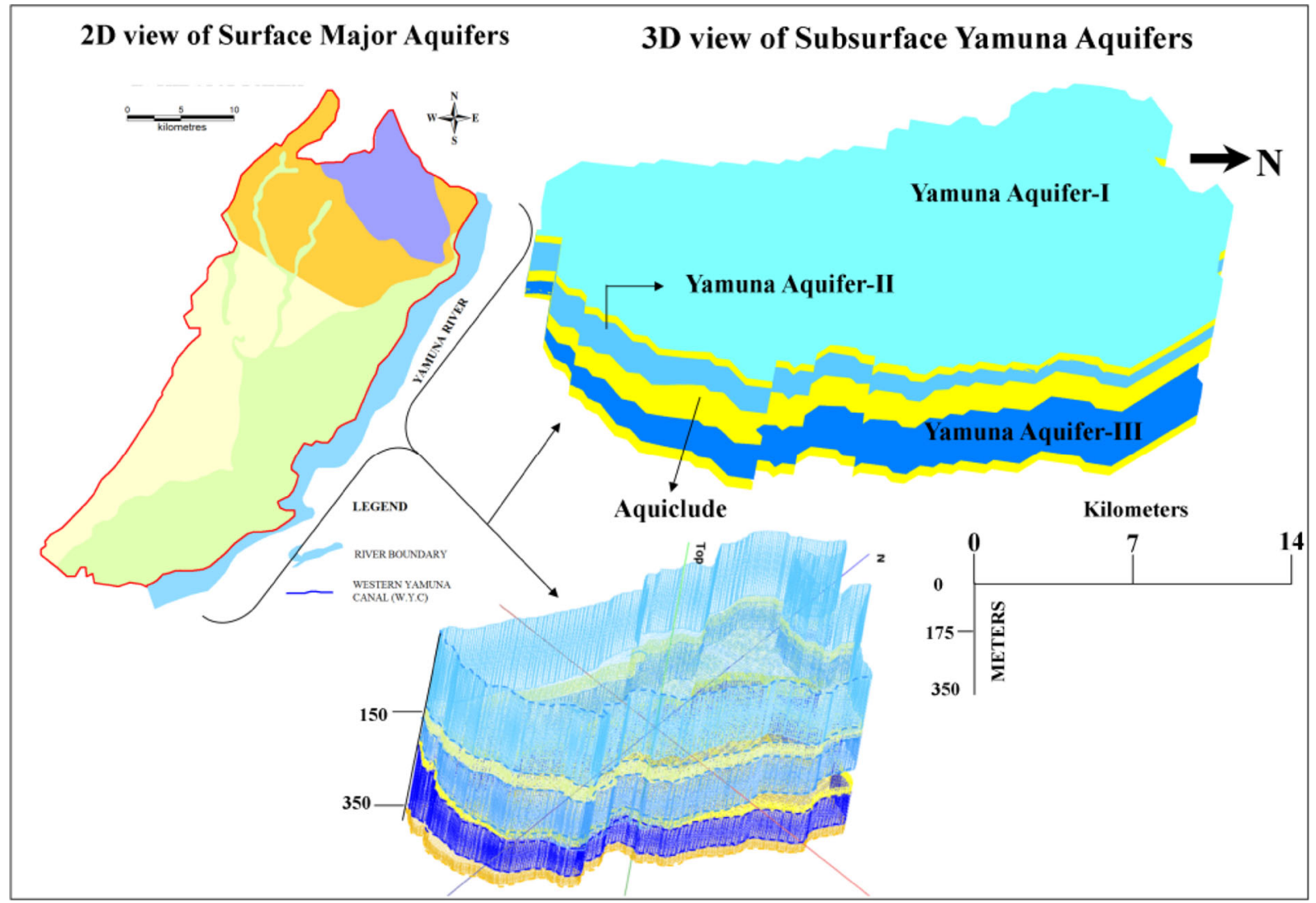

Figure 4. Synoptic views of aquifer systems in the study area.

All model parameters, such as depth to water, net recharge, aquifer media, soil media, topography, impact of vadose zone, hydraulic conductivity of the aquifer and electrical conductivity of ground water, have been considered at 27 regularly monitored stations. This model employs a numerical ranking system that assigns relative weights to various parameters that help in the evaluation of relative ground water vulnerability to contamination. The hydrogeologic settings, which make up the acronym, DRASTIC-EC formula, have been described in the following section. Each of the eight parameters has been mapped and classified either into ranges or into significant media types that have an impact on pollution. Each factor or parameter has been assigned a subjective rating. Weight multipliers have been then used for each factor to balance and enhance its importance. The final vulnerability map is based on the DRASTIC-EC index (Di) which is computed as the weighted sum overlay of the eight layers using the following equation:

DRASTIC-EC Index

$$
\begin{aligned}
= & D r \times D w+R r \times R w+A r \times A w+S r \times S w \\
& +T r \times T w+I r \times I w+C r \times C w+E C r \times E C w
\end{aligned}
$$

where $D=$ depth to water table, $R=$ aquifer recharge, $A=$ aquifer media, $S=$ soil media, $T=$ topography/slope, $I=$ impact of the vadose zone, $C=$ hydraulic conductivity and $E C=$ electrical conductivity; $r$ and $w$ are the rating and weight of each parameter, as defined in table 1.

\section{Results and discussion}

\subsection{Hydrogeological studies}

Hydrogeological field traverses were made during 2014-2015 to assess the seven DRASTIC-EC parameters. Hydrogeological surveys include ground water monitoring from the observation wells established in the study area, ground water exploration for delineation of aquifer geometry, estimation of aquifer parameters through pumping tests, determination of soil infiltration rates, analysis of soil texture in order to understand the grain size variations and also to find the depositional environment, etc. 


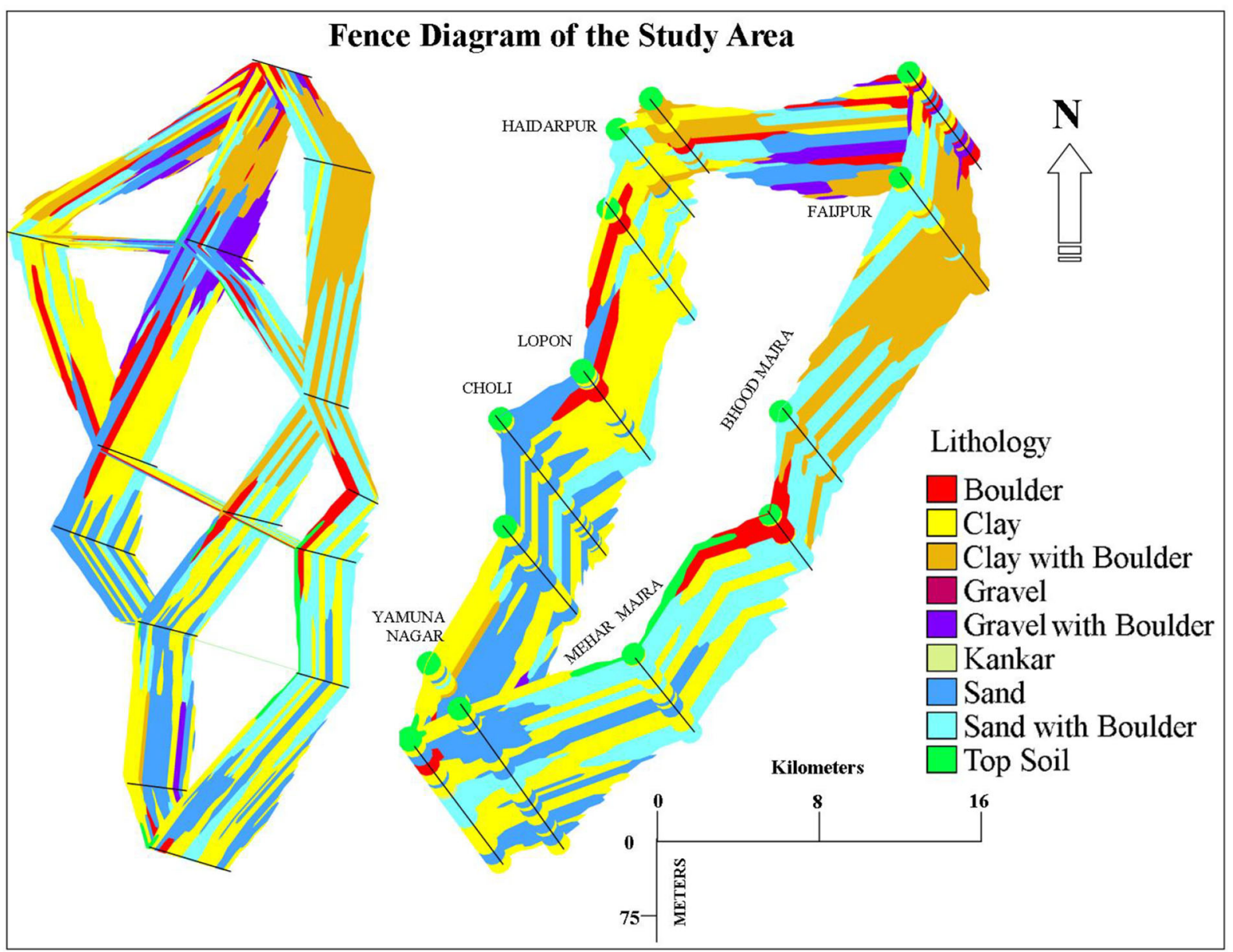

Figure 5. Three-dimensional (3D) lithological fence diagram of the unconfined aquifer.

\subsubsection{Depth to water level (D)}

Depth to water level (DTW) is an important parameter because it determines the depth of material through which a contaminant must travel before reaching the saturated aquifer (Aller et al. 1987). In the present study, the DTW is used to demarcate the depth to the top of the aquifer.

In general, there is a greater chance for attenuation to occur as the DTW increases because deeper water levels infer longer travel time for ground water. Shallow DTW does not allow contaminated infiltrating waters enough contact time with the aquifer material for their associated attenuation process to be effective in removing contamination. Therefore, DTW is assigned the maximum weight (5) in determining vulnerability using DRASTIC model. The DTW level in the study area ranges from a minimum of $1.2 \mathrm{~m}$ to a maximum of $36.8 \mathrm{~m}$ below ground level (bgl) during May 2015 (figure 3a). Rahman (2008) assigned ratings (Dr) of 10,9 and 7 to DTW of $<5,5-15$ and $>15 \mathrm{mbgl}$, respectively, which have been adopted in this work (table 1). Therefore, by multiplying $D r$ with $D w$, an index value for DTW for each ground water monitoring station has been obtained and contoured for the area as whole (figure 3b).

\subsubsection{Net recharge $(R)$}

The primary source of ground water is rainfall, and the net recharge is the amount of rain water that penetrates the ground surface per unit surface area of the soil. This is the principal vehicle that transports contaminants to the ground water. The more the recharge, the greater is the chances of the contaminant to be transported to the ground water table. In areas where the aquifer is unconfined, recharge to the aquifer usually occurs more readily and the pollution potential is generally greater than in areas with confined aquifers. This recharged water is thus available to 


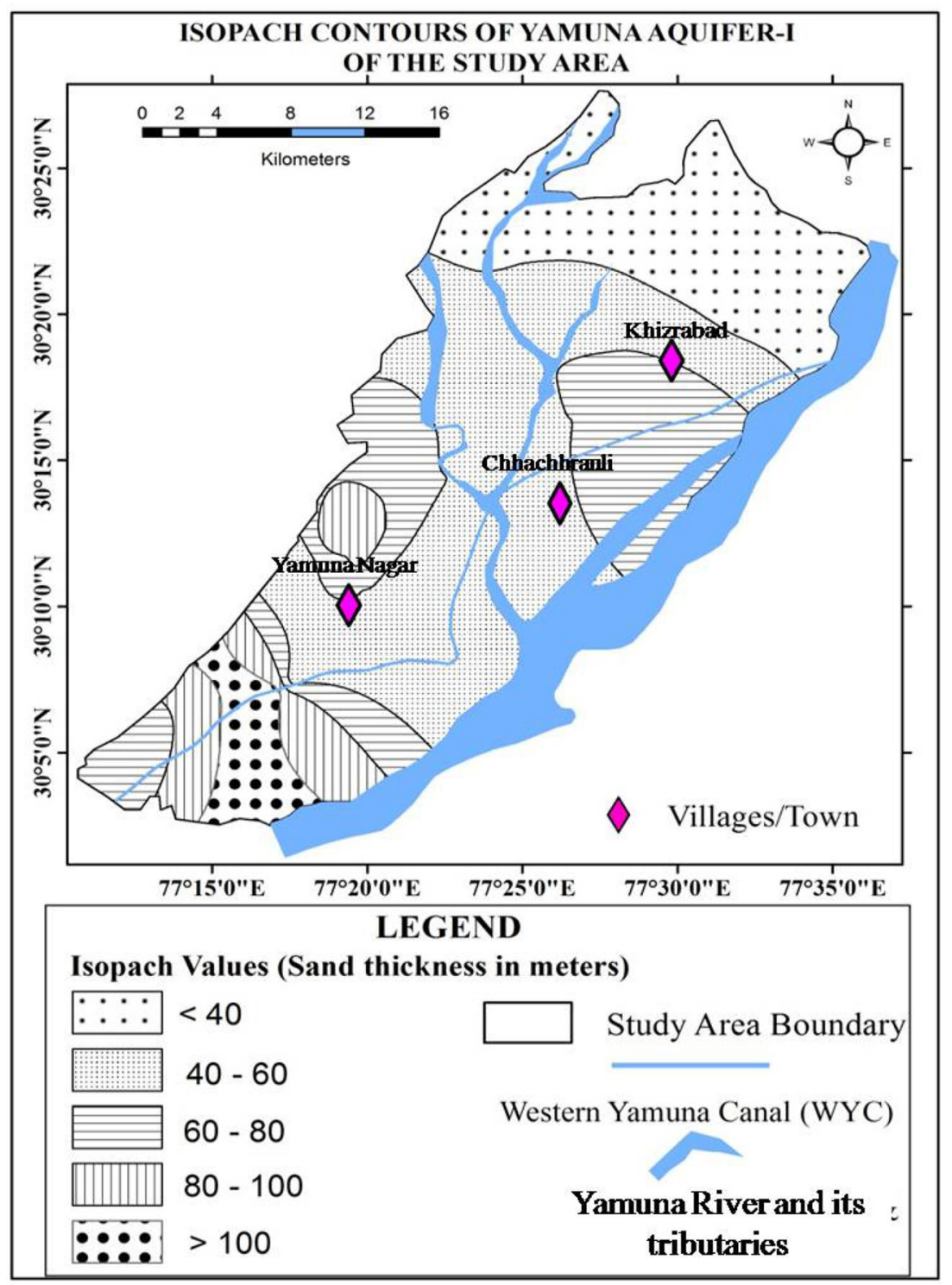

Figure 6. Isopach map showing sand/gravel thickness of unconfined aquifer (Yamuna Aquifer I) in the study area.

Table 3. Major soil types, their description and rate of infiltration in the study area.

\begin{tabular}{|c|c|c|}
\hline Major soil type* & Description* & $\begin{array}{l}\text { Infiltration rate } \\
\qquad(\mathrm{mm} / \mathrm{hr})\end{array}$ \\
\hline Soils of recent flood plain & $\begin{array}{l}\text { Coarse sandy soils and coarse } \\
\text { loamy, calcareous soils }\end{array}$ & 10 to $>50$ \\
\hline Soils of Siwalik Hills & Loamy skeletal soils & 10 to 50 \\
\hline Soils of piedmont plain & Fine loamy soils & $<10$ \\
\hline Soils of older alluvial plain & $\begin{array}{l}\text { Fine clayey and loamy, } \\
\text { calcareous soils }\end{array}$ & $<10$ \\
\hline Soils of active flood plain & $\begin{array}{l}\text { Coarse loamy, calcareous } \\
\text { stratified soils }\end{array}$ & $<10$ \\
\hline
\end{tabular}

transport a contaminant vertically to the water table and horizontally within the aquifer (Aller et al. 1987).
The study area falls in the Chhachhrauli and Jagadhri administrative blocks of the Yamuna Nagar District in the state of Haryana. The net 


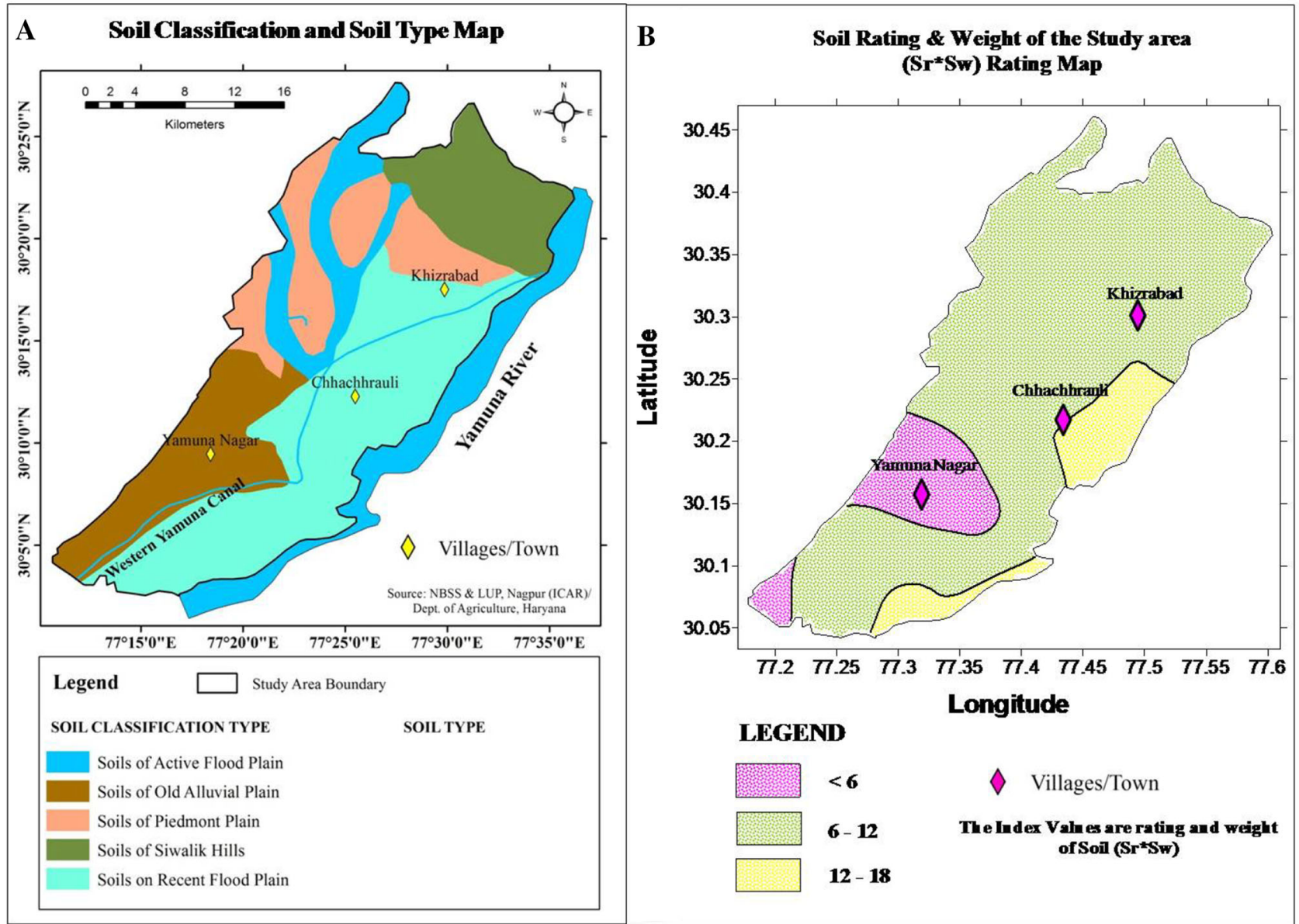

Figure 7. (a) Map showing soil classification and soil type. (b) Soil ratings and weights in the study area.

Soil Type vs Infiltration Rate $(\mathrm{mm} / \mathrm{Hr})$

(Total Area (800 Sq.Km)

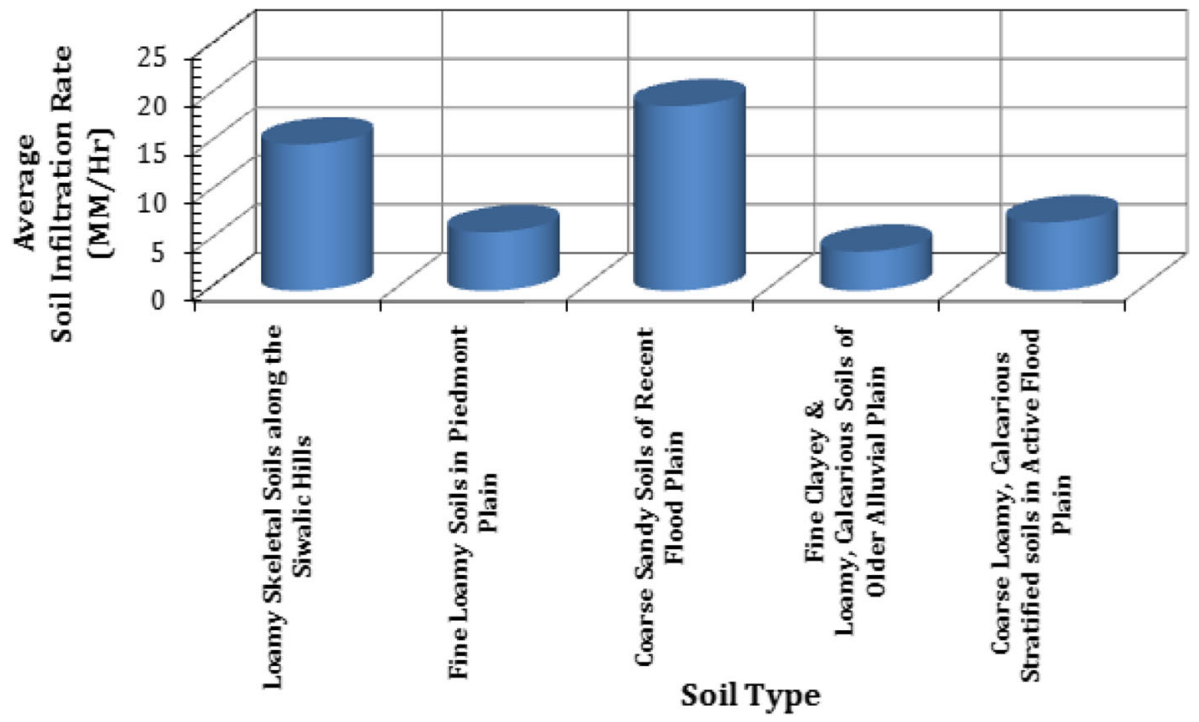

Figure 8. Soil types and their average infiltration rates $(\mathrm{mm} / \mathrm{hr})$. 


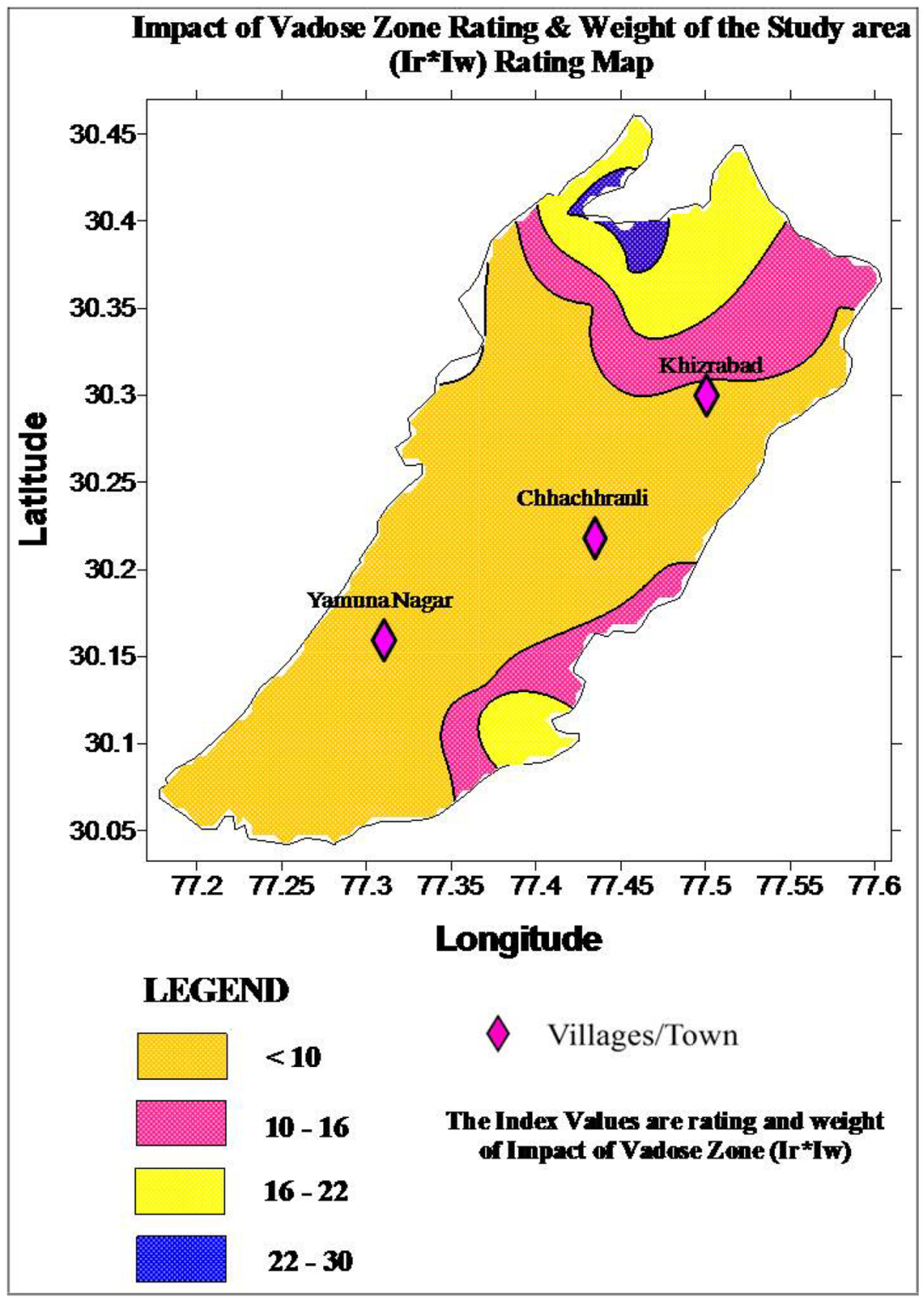

Figure 9. Index map showing impact of vadose zone in the study area.

recharge for these blocks has been estimated from the water table fluctuation method as per the Ground water Estimation Committee (GEC) 1997 methodology (GWREC 1997) (table 2). In DRASTIC model, the standard weight $(R w)$ for net recharge is considered as 4 , and if the annual net recharge is more than $254 \mathrm{~mm}$ in an area, then the standard rating for recharge $(R r)$ is considered as 9 (table 1 ). The net recharge in the study area is $>300 \mathrm{~mm}$, and therefore, it is assigned a common $R r$ of 9 . Thus, for each monitoring station in the two blocks of the study area, the index recharge $R$ is estimated at 36, i.e., $R=$ $4(R w) \times 9(R r)$.

\subsubsection{Aquifer (A)}

Aquifer is a water-bearing formation which is able to store and yield significant quantities of water to wells or springs (Todd and Mays 2015). In order to demarcate the aquifers, the existing litholog data of the exploratory wells and tube wells drilled by Central Ground Water Board (CGWB), and Haryana State Government as well as private agencies were compiled and modelled into 3D stratigraphic synoptic views using ROCKWORKS version16 software. Aquifers thus have been grouped into three based on this analysis: Yamuna Aquifer-I, Yamuna Aquifer-II, and Yamuna Aquifer-III. These aquifers 


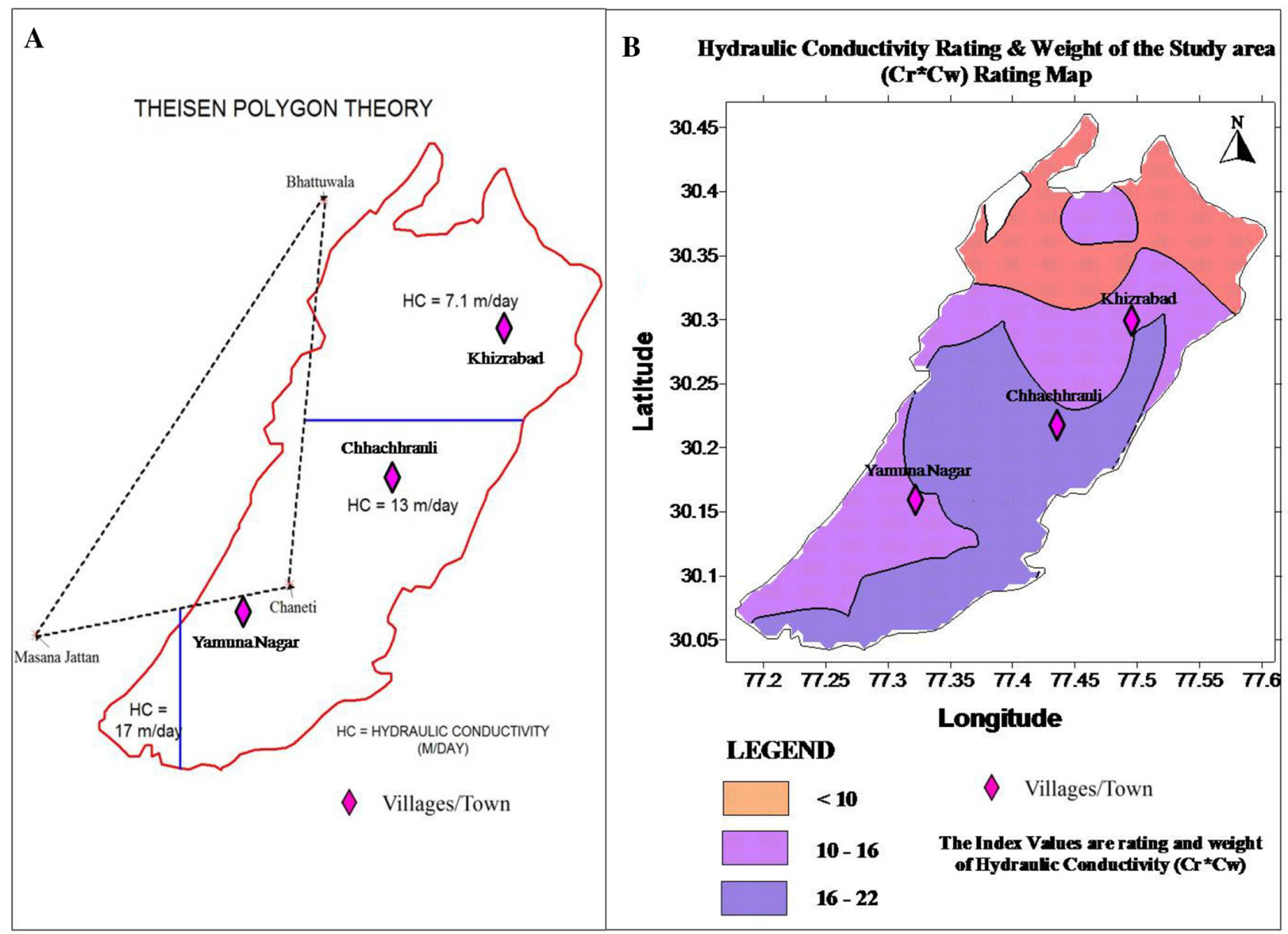

Figure 10. (a) Distribution of hydraulic conductivity through Thiessen Polygon method in the study area. (b) Hydraulic conductivity index map of the study area in contour form.

have the vertical extensions up to $145 \mathrm{~m}, \sim 171$ to $\sim 264 \mathrm{~m}$ and 282 to $\sim 356 \mathrm{~m}$, respectively (figure 4) separated by $20 \mathrm{~m}$ thick clay layer. Yamuna Aquifer-I is the unconfined aquifer and Yamuna Aquifers II and III are confined aquifers, which are under pressure. Yamuna Aquifer-I consists of coarse sand, clay and gravelly materials and holds isopach zones of thickness $65-90 \mathrm{~m}$ within it.

Unconfined aquifers get easily contaminated by anthropogenic activities and geogenic sources. Hence, more detailed study is needed to understand Yamuna Aquifer-I, such as the potential granular zones existing in the aquifer, aquifer disposition system, and also the socio-economic structure of the area in order to identify possibilities of ground water vulnerability. For this reason, the existing lithologic data of the unconfined aquifers have been used to prepare a 3D fence diagram (figure 5) as well as an isopach map that shows the sand/gravel thickness (figure 6). The surface soil samples have also been collected and texturally analysed. Soils consist of sand $(71 \%)$, clay $(28 \%)$ and slime (shell materials) (1\%). Further, $71 \%$ of the sandy soils are mostly coarse- to medium-grained sand with grain size of $250-90 \mu \mathrm{m}$ (0.25-0.09 mm). Maximum number of samples $(93 \%)$ are deposited by river tractive current environment with graded suspension and no rolling, which indicates that the sediments were deposited by flood deposition without further movement of material.

Generally, larger the grain size and aquifer parameters, higher are the permeability and lower is the attenuation capacity. Therefore, greater is the pollution potential (Umar et al. 2009). Homogeneous aquifer materials with the dominance of sand mixed with gravel/clay/boulders is assigned a rating of 6-8 (Aller et al. 1987; Rahman 2008). In the study area, the existing dominant material is coarse sand as confirmed through the textural analysis and isopach studies. Therefore, a 


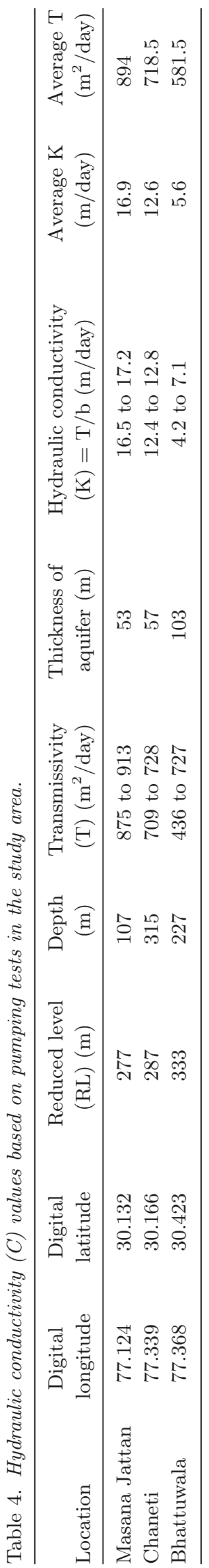

uniform rating $(A r)$ of 8 is taken for the unconfined aquifer (table 1). The recommended weight for the aquifer media $(A w)$ is 3 (Aller et al. 1987). Thus, for each monitoring station, the $A$ index is calculated at 24, i.e., $A=3(A w) \times 8(A r)=24$.

\subsubsection{Soil (S)}

Soils are the weathered materials of geological formations existing in the study area. The soil categorization is mainly done based on the dominant geomorphic units as shown in table 3 and figure $7(\mathrm{a})$. The soil infiltration rates in table 3 were calculated using a single ring infiltrometer. The results are shown in figure 8. The majority of soils in the study area are loamy-skeletal soil (coarse sand) with coverage of $\sim 435 \mathrm{~km}^{2}$ and infiltration rate up to $50 \mathrm{~mm} / \mathrm{hr}$. The remaining area of $\sim 365 \mathrm{~km}^{2}$ has fine to coarse loamy, clayey, calcareous stratified soils with the infiltration rate of $<10 \mathrm{~mm} / \mathrm{hr}$.

The four types of soils in the study area, viz., loam, sand, sandy loam and clay, correspond to ratings $(S r)$ of $5,9,6$, and 1 , respectively (table 1 ), and are assigned a common weight $(S w)$ of 2 in DRASTIC model. Thus, the soil index is calculated for each monitoring station by multiplying $S w$ with $S r$, i.e., $S=S w * S r$ and shown in contour form in figure $7(\mathrm{~b})$.

\subsubsection{Impact of vadose zone (I)}

The unsaturated zone above the water table and below the soil water zone and part of the zone of aeration is known as the vadose zone (Todd and Mays 2015). The texture of the vadose zone determines how long a contaminant will travel through it. The media also controls the path length and routing, thus affecting the time available for attenuation and the quantity of material encountered. The materials at the top of the vadose zone also exert an influence on soil development (Aller et al. 1987). In the present study, impact of the vadose zone has been calculated by the harmonic mean approach (Hussain et al. 2006), as shown in the equation below.

$$
I r=\frac{T}{\sum_{i=1}^{N} \frac{T i}{I r i}}
$$

where $I r=$ the weighted harmonic mean of the vadose zone, $T=$ total thickness of the vadose zone, $T i=$ thickness of the layer $I$, and $I r i=$ rating of layer $i$. 


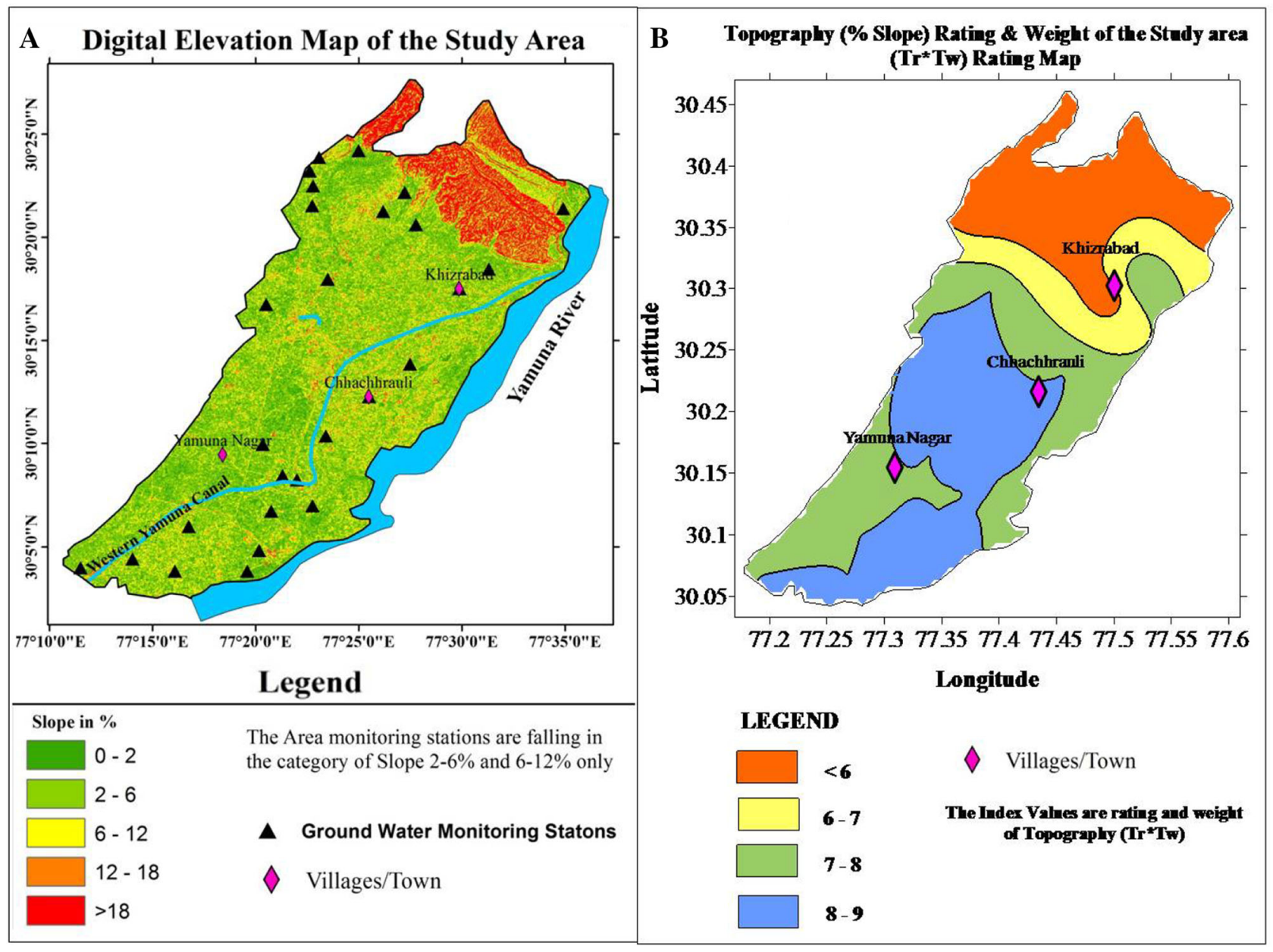

Figure 11. (a) Percent slope map of the study area. (b) Topography index map of the study area.

Based on the lithology of the drilled holes, the vadose zone in the study area consists of clay, silt, fine and loamy sand and gravel, which correspond to a rating (Ir) of 1 (Hussain et al. 2006) (table 1 ) and a weight $(I w)$ of 5 in the DRASTIC model. The calculation for each monitoring station is thus generated by multiplying $I r$ and $I w$ and shown in figure 9 for the area as a whole.

\subsubsection{Hydraulic conductivity $(C)$}

Hydraulic conductivity is a measure of the permeability of the media, and is controlled by the amount and interconnection of void spaces within the aquifer, which may occur as a consequence of factors such as inter-granular porosity, fracturing and bedding planes (Todd and Mays 2015). Hydraulic conductivity refers to the ability of the aquifer materials to transmit water, which in turn, controls the rate at which ground water will flow under a given hydraulic gradient. This rate of ground water flow also controls the rate at which a contaminant will move away from the point it enters the aquifer. An aquifer with high conductivity is vulnerable to substantial contamination as a plume of contamination can move easily through the aquifer (Rahman 2008).

Conductivity values were obtained through pumping tests at three locations of exploratory well sites inside and adjoining the study area, i.e., at Bhattuwala $4 \mathrm{~km}$ away from the basin boundary in the north-western part, Chaneti within the study area and Masana Jattan about $10 \mathrm{~km}$ from the basin boundary in the south-western part (figure 10a). Results are shown in table 4 . Thiessen polygon method was used to distribute the conductivity values throughout the area, as explained in figure 10(a). Qinghai et al. (2007) have modified the conductivity ratings $(C r)$ (table 1 ), i.e., conductivity of 5-10 and 10-15 m/day have $C r$ of 2 and 4, respectively. DRASTIC model weight $(\mathrm{Cw})$ of conductivity is taken as 3 . Thus, for each monitoring well site, the conductivity index is calculated by multiplying their respective $\mathrm{Cr}$ values 


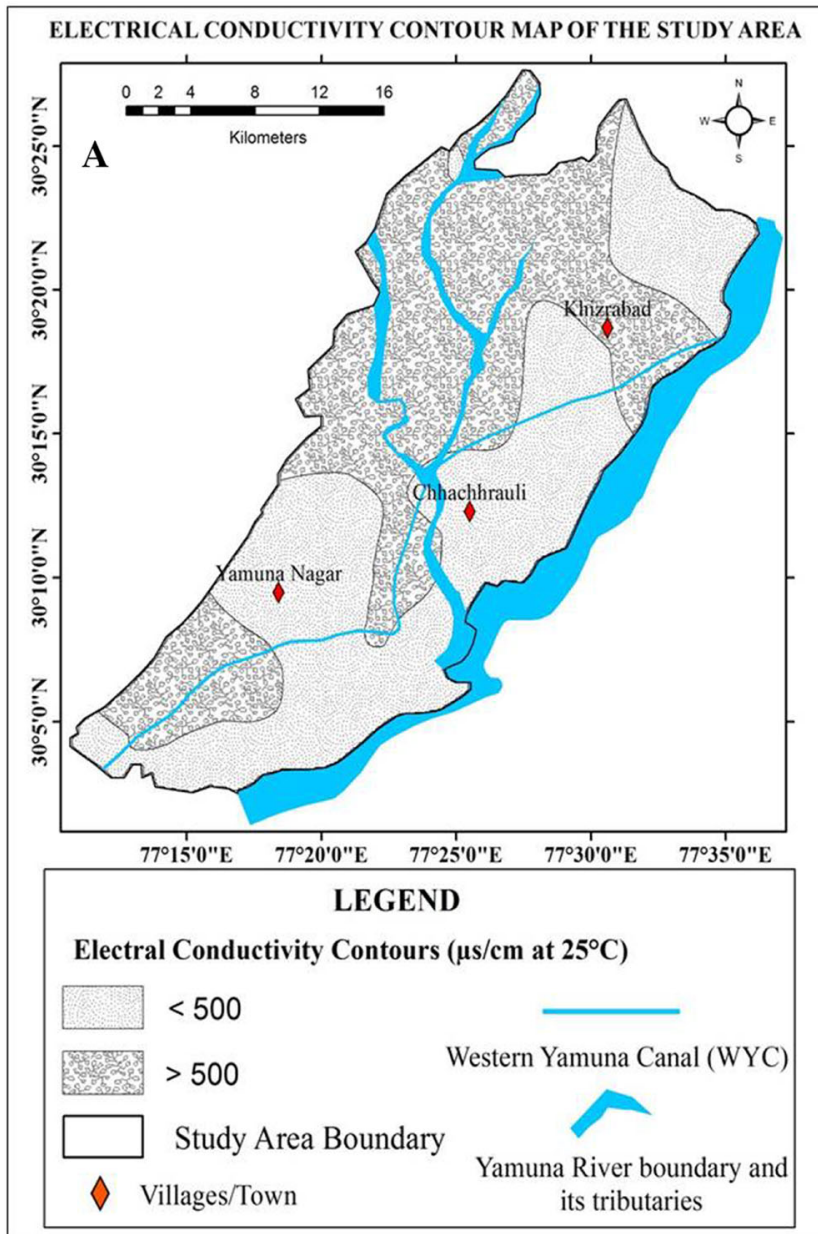

\section{Electrical Conductivity (EC) index map of the study area}

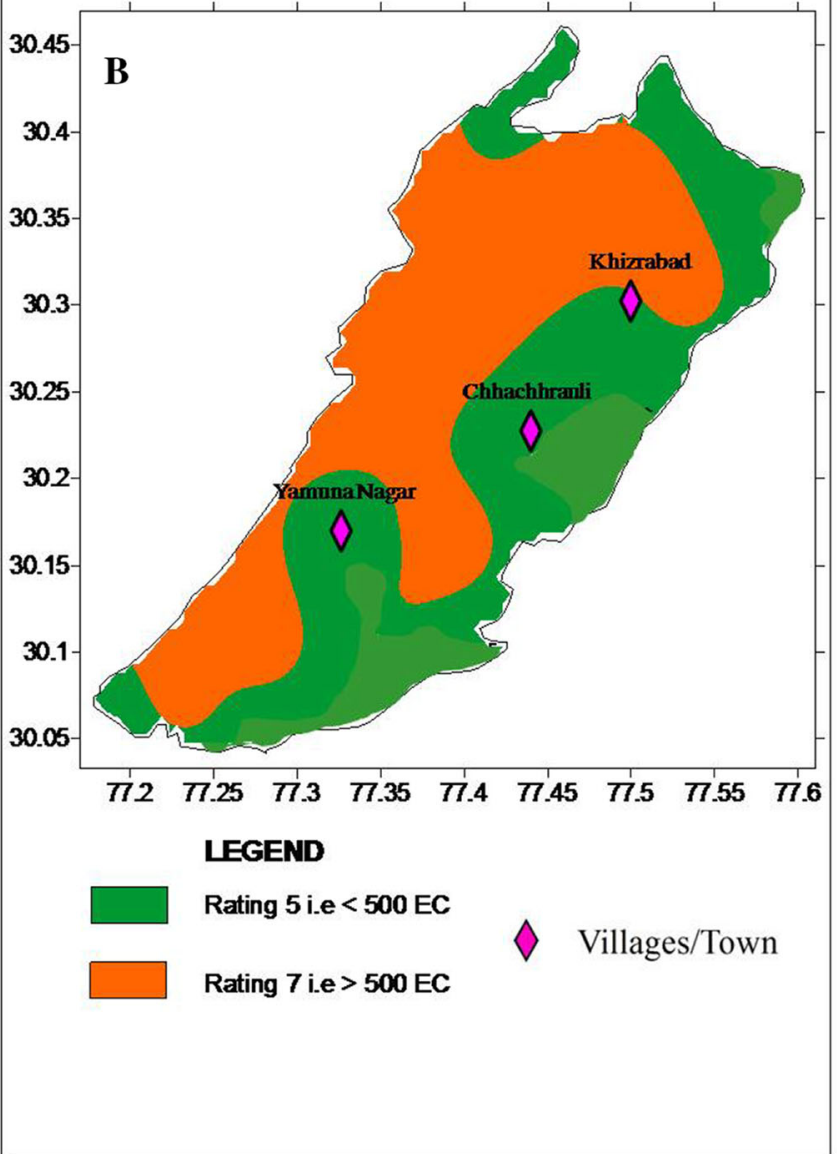

Figure 12. (a) Electrical Conductivity (EC) Contouring map of the study area. (b) EC index map of the study area.

as determined from figure 10(a) and $C w$. A contour diagram for $C$ is shown in figure 10(b).

\subsection{Geospatial studies: Topography analyses}

Topography refers to the slope and slope variability of the land surface. Basically, topography helps control the likelihood that a pollutant will run off down the slope or else remain on the surface in an area long enough to infiltrate. This is particularly important in activities such as the application of pesticides and herbicides where effect of the contaminant tends to be cumulative. Topography influences soil development and, therefore, has an effect on the attenuation of pollutants. Topography is also important from the standpoint that the gradient and direction of flow in water table conditions can often be inferred from the general slope of the land. Typically, steeper slopes signify higher ground water velocity (Aller et al. 1987).
Topography/slope map is generated for the study area using Cartosat-1 satellite data launched by Indian Space Research Organisation (ISRO) (NRSC-ISRO 2008) on the platform of ArcGIS 10 software. The elevation ranges from 196 to $611 \mathrm{~m}$ above mean sea level. The Carto-DEM image was initially geographically corrected and then using the slope tool, the slope map was generated (figure 11a) after normalization of the index values with percent slopes of $0-2,2-6,6-12,12-18$ and $>18$. Ground water monitoring stations in the study area are located in slope percent of 2-6 and 6-12 mainly. Accordingly, slope rating ( $T r$ ) for each monitoring station is given with respect to slope percent. For example, $\operatorname{Tr}=9$ for a slope percent of $2-6$ and $\operatorname{Tr}=5$ for a slope percent of $6-12$. Slope is assigned a weight of 1 in the DRASTIC model (table 1 ). Accordingly, slope index $(T=T w \times T r)$ for each monitoring station is calculated and an index map is generated for the area as a whole (figure 11b). 


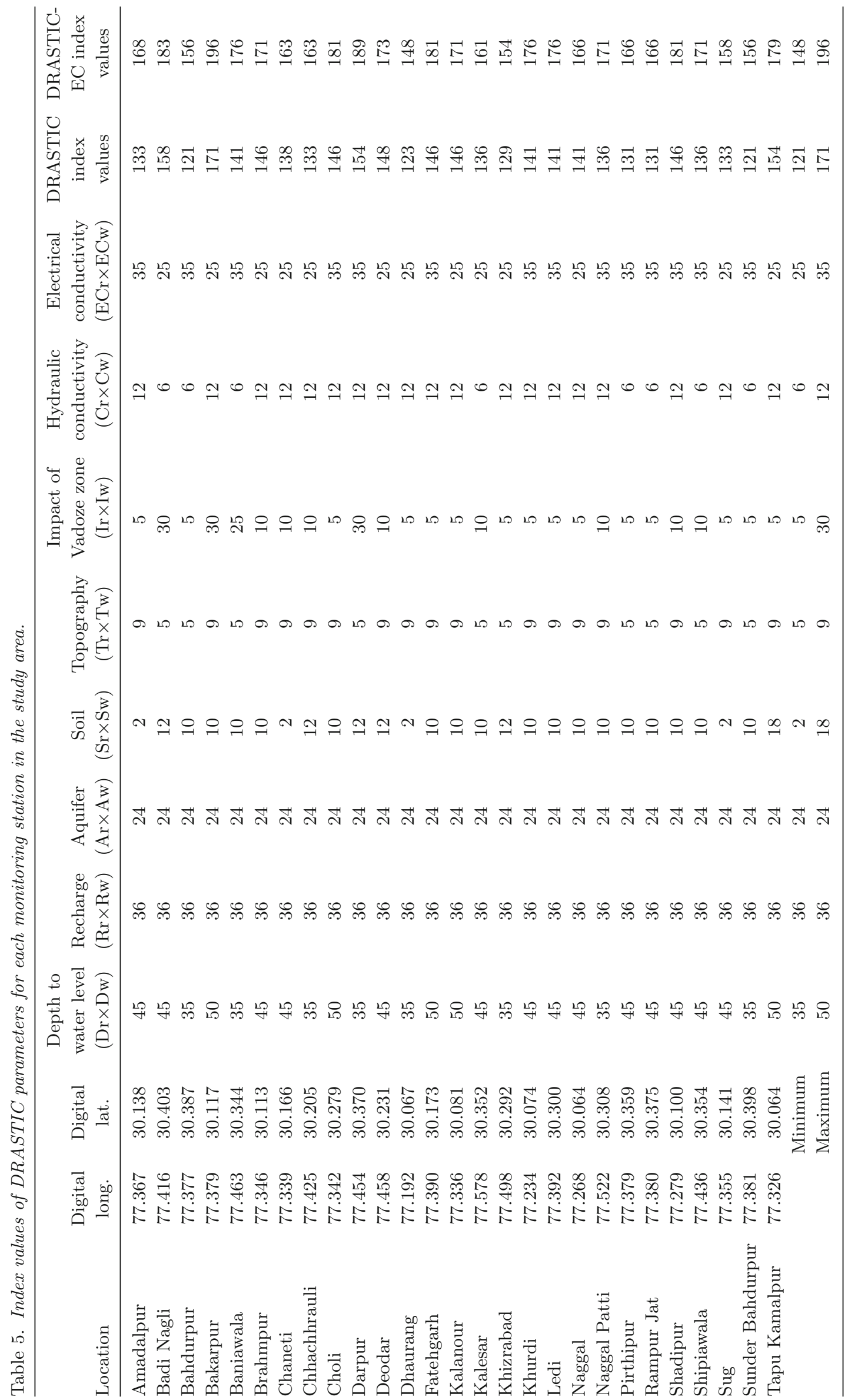




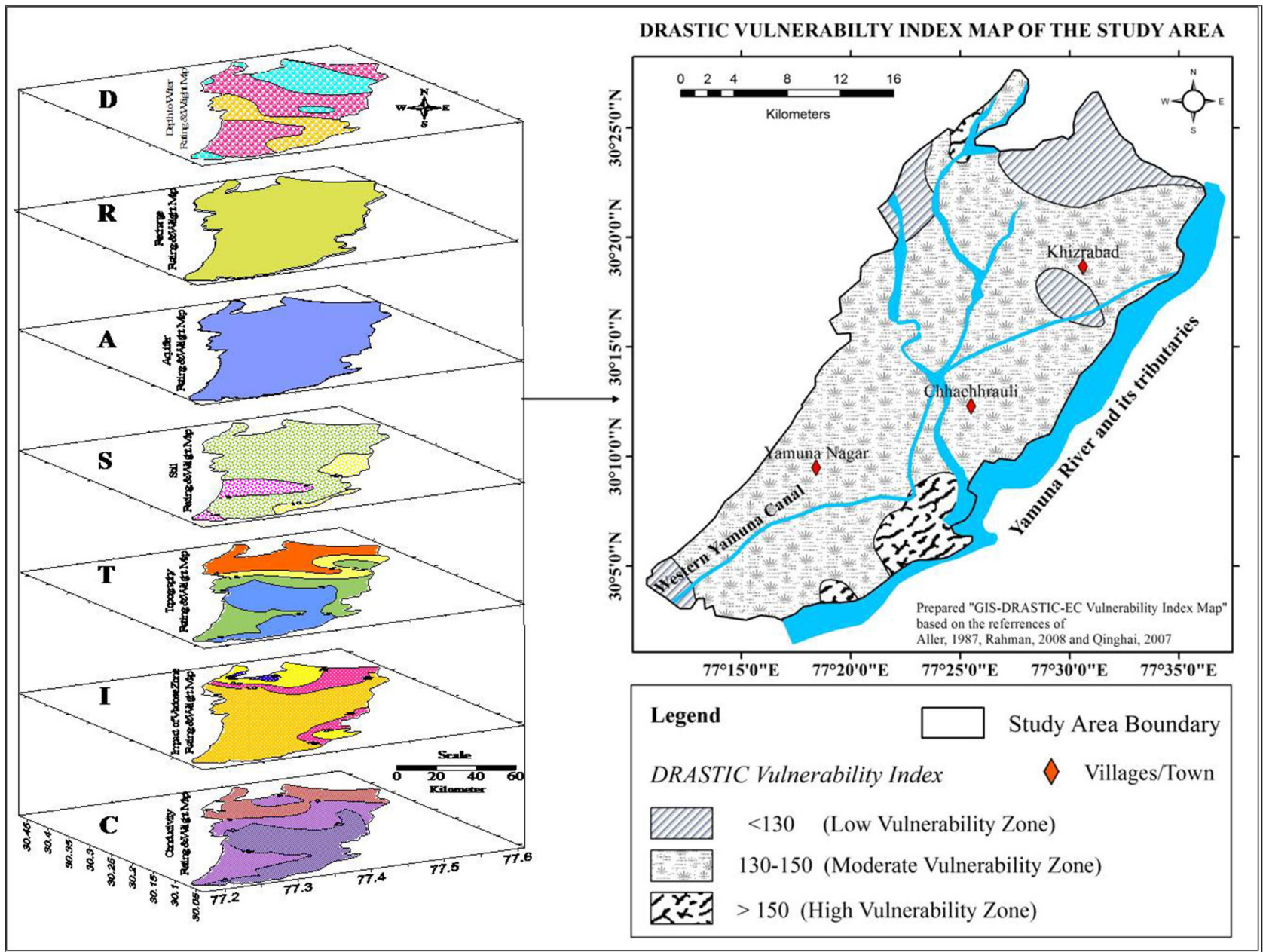

Figure 13. DRASTIC vulnerability index map of the study area.

\subsection{Hydro-geochemical studies: Electrical conductivity (EC) of ground water}

Electrical conductivity is directly related to the concentration of salts dissolved in water, and therefore to the total dissolved solids (TDS). It is a field parameter measured along with temperature and $\mathrm{pH}$ and gives first-hand information about the quality of ground water. Since it is difficult to measure TDS in the field, EC of the water is used as a measure. The conversion from EC to TDS depends on the types of minerals and salts dissolved in water. This conversion factor can be found in published tables. If the actual conversion factor cannot be found, then 0.67 is frequently used as an approximate conversion factor, i.e., $\mathrm{EC} \times 0.67=\mathrm{TDS}($ Thomas 2017) .

Electrical conductivity was measured in the field itself at the monitoring stations by using a portable EC meter. It varied between 356 and $843 \mu \mathrm{S} / \mathrm{cm}$ at $25^{\circ} \mathrm{C}$. Sarma and Narayanaswamy (1981) have given a four-fold classification of EC for drinking water, viz., low EC: $<500 \mu \mathrm{S} / \mathrm{cm}$, medium EC (Class I): $500-1000 \mu \mathrm{S} / \mathrm{cm}$, medium EC (Class II): $1000-3000 \mu \mathrm{S} / \mathrm{cm}$, and high EC: $>3000 \mu \mathrm{S} / \mathrm{cm}$. Ground water in the study area is mostly fresh with EC values within $1000 \mu \mathrm{S} / \mathrm{cm}$. Therefore, EC values have been contoured in the whole area taking $\mathrm{EC}<500 \mu \mathrm{S} / \mathrm{cm}$ and $\mathrm{EC}>500 \mu \mathrm{S} / \mathrm{cm}$ (figure 12a). Ratings $(E C r)$ are taken as 5 and 7 for these two zones, respectively (table 1). Weight for EC is taken as 5 considering the importance it plays in characterizing the chemical quality of ground water. Accordingly, EC index $(E C=E C w \times E C r)$ for each monitoring station is calculated and an index map is generated for the area as a whole (figure 12b).

\subsection{Integration of DRASTIC parameters and model generation}

Rating and weight of each parameter along with the final index value generated for each monitoring station by multiplying these two 


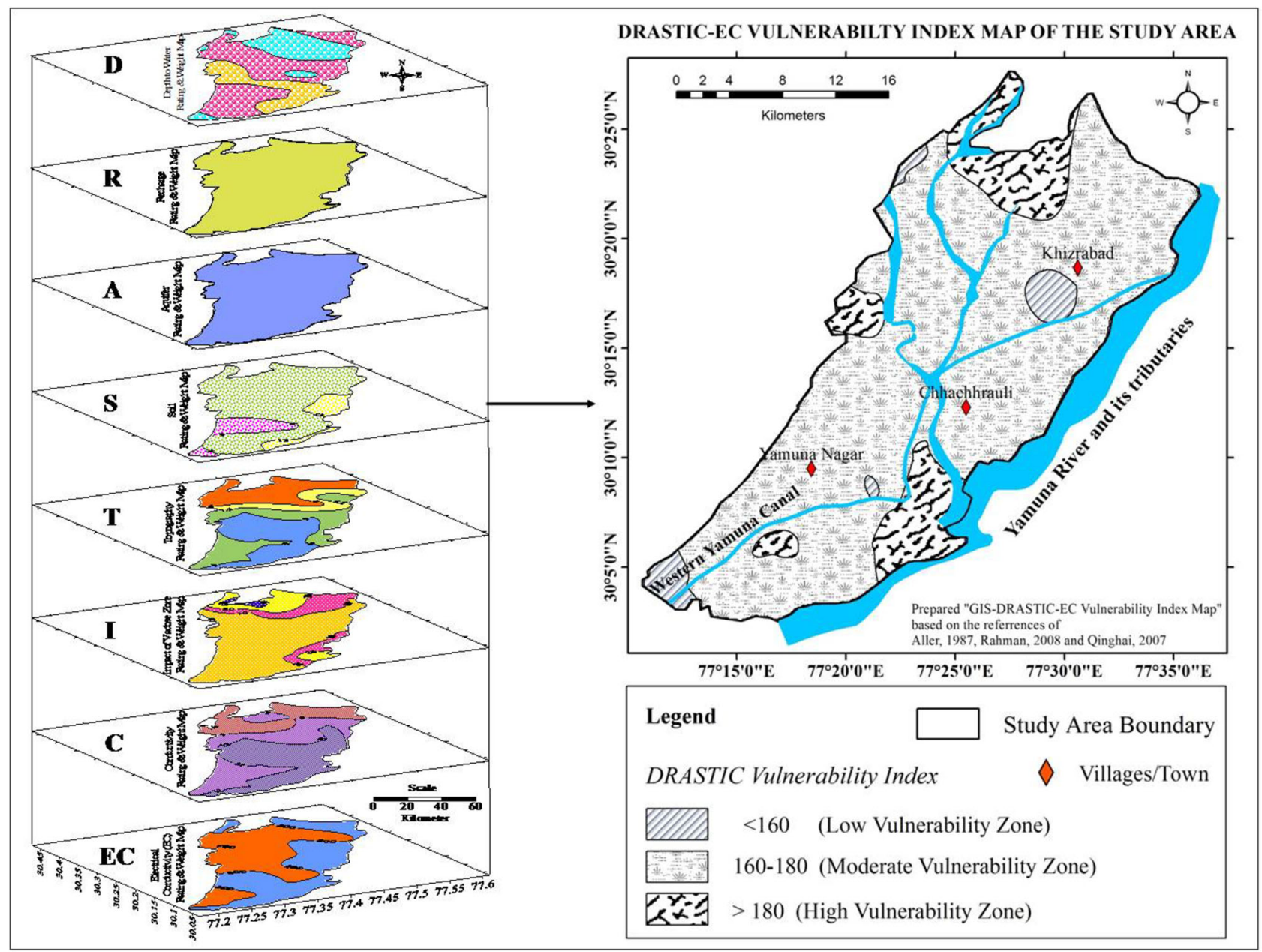

Figure 14. DRASTIC-EC vulnerability index map of the study area.

components are given in table 5. The DRASTIC index values range from 121 to 171, which have been classified into three distinct zones, such as $<130,130-150$ and $>150$ corresponding to low, moderate and high vulnerability zones, respectively. The final GIS-based DRASTIC vulnerability map of the study area is shown in figure 13 . On the contrary, the DRASTIC-EC index values range from 148 to 196, which also have been classified into three distinct zones, such as $<160,160-180$ and $>180$ corresponding to low, moderate and high vulnerability zones, respectively. The final GIS-based DRASTIC-EC vulnerability map of the study area is shown in the figure 14. A comparison between figures 13 and 14 representing DRASTIC and DRASTICEC models, respectively, shows that DRASTICEC model identifies more areas, which are highly vulnerable. For example, in DRASTIC model, the areal extent of low, medium and high vulnerable areas are in the order of $13 \%\left(105 \mathrm{~km}^{2}\right), 80 \%$ $\left(640 \mathrm{~km}^{2}\right)$ and $7 \%\left(55 \mathrm{~km}^{2}\right)$, respectively, while in the DRASTIC-EC model, the respective areal extents are $5 \%\left(37 \mathrm{~km}^{2}\right), 80 \%\left(639 \mathrm{~km}^{2}\right)$ and $15 \%$ $\left(124 \mathrm{~km}^{2}\right)$. Area which was of low vulnerability in the northern parts has been identified as high vulnerable zone in the modified model. Two of the highly polluted locations, Badi Nagli (Sample no. 1) and Darpur (Sample no. 5) are located in this area. DRASTIC-EC model, therefore, seems to be a better model compared to the conventional DRASTIC model.

\subsection{Statistical approach: Single parameter sensitivity analysis (SPSA)}

SPSA is aimed at comparing the 'theoretical' weight of each parameter with that of its 'effective' or 'actual' weight. The effective weight is worked out with the help of the following formulae:

$$
E w=((P r \times P w) / v) \times 100
$$


where $E w=$ effective weight, $\operatorname{Pr}=$ parameter rating, $P w=$ parameter weight, and $v=$ overall vulnerability index. These values have been derived in table 5 and summarised in table 6 . If the mean of effective weight\% of a parameter is more than its theoretical weight\% (i.e., theoretical weight of each parameter divided by the total theoretical weights of all parameters with the resultant multiplied by 100), then the parameter is more significant for abetting ground water contamination, such as in case of DTW ( $E w: 25.25 \%>T w: 17.86 \%)$, net recharge ( $E w: 21.25 \%>T w: 14.29 \%)$, aquifer media (Ew: $14.16 \%>T w: 10.71 \%)$ and topography $(E w: 4.43 \%>$ Tw: $3.57 \%)$. Effective weight of EC (17.77) is very close to its theoretical weight (17.86) with a difference of only 0.09 , which shows that EC does play an important role in the assessment of ground water contamination of an area, and should be included in the DRASTIC model.

\subsection{Model validation through hydro-geochemical studies}

Seventeen ground water samples were collected randomly from the first aquifer (unconfined) in the study area and analysed in the Chemical Laboratory of Central Ground Water Board (CGWB), North Western Region, Chandigarh, India as per APHA (1992). Three samples were collected from each location, one for analysis of basic chemical parameters, other for heavy metal and the third one for analysis of iron. The water samples were collected and stored in 1-litre capacity clean plastic bottles. Before collection, the bottles were properly washed and rinsed with the water to be sampled. The wells were pumped for about half-an-hour before collection of samples so that stagnant water, if any, was completely removed from storage within the well assembly. Samples for heavy metal analysis were treated with $2 \mathrm{ml}$ nitric acid $\left(\mathrm{HNO}_{3}\right)$ and those for iron analysis were treated with $2 \mathrm{ml}$ of hydrochloric acid $(\mathrm{HCl})$. All samples were collected from a depth of less than $75 \mathrm{~m}$. Analytical results are shown in table 7 . In addition to these 17 samples analysed, chemical data of eight locations lying within the study area were collected from the National Rural Drinking Water Programme (NRDWP-MDWS 2015). Out of these 25 samples, few chemical parameters are above the permissible limits prescribed by the Bureau of Indian Standards (BIS 2012) (table 7). The sampling locations were superimposed on the DRASTIC-EC index map (figure 15) to actually pinpoint the

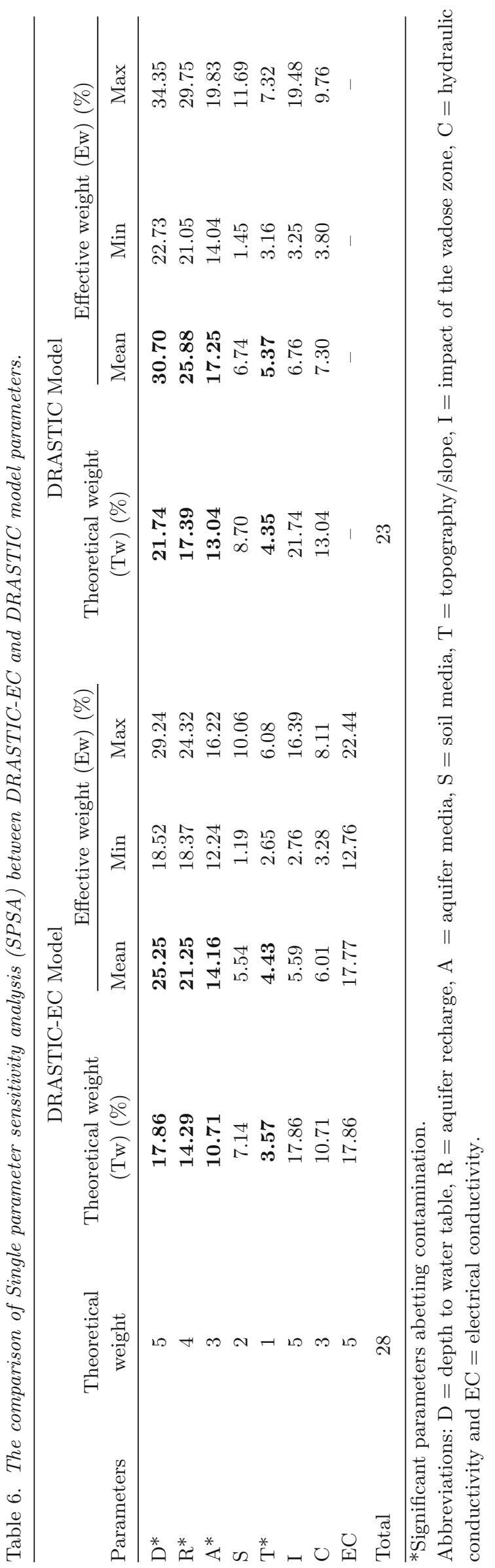




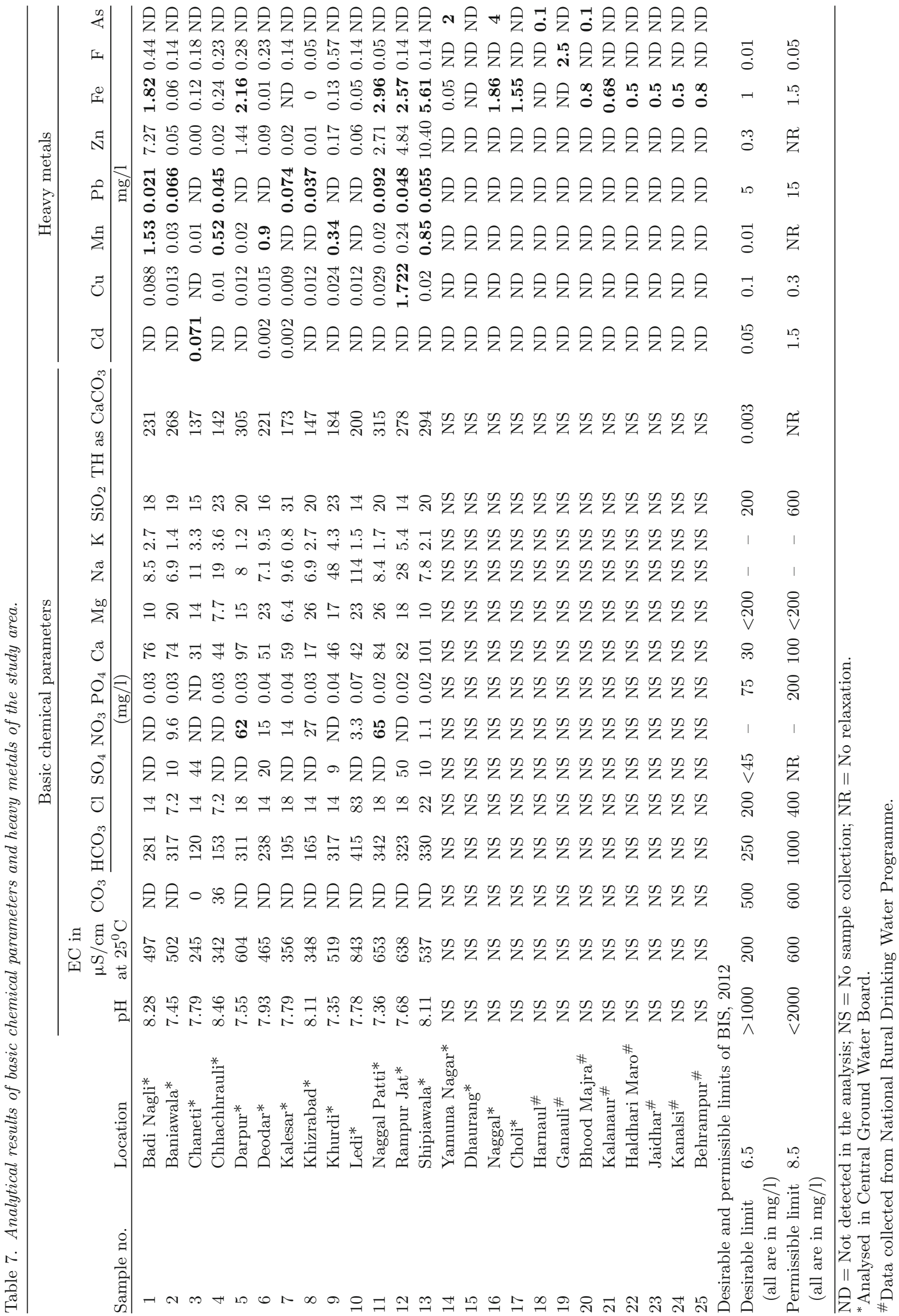




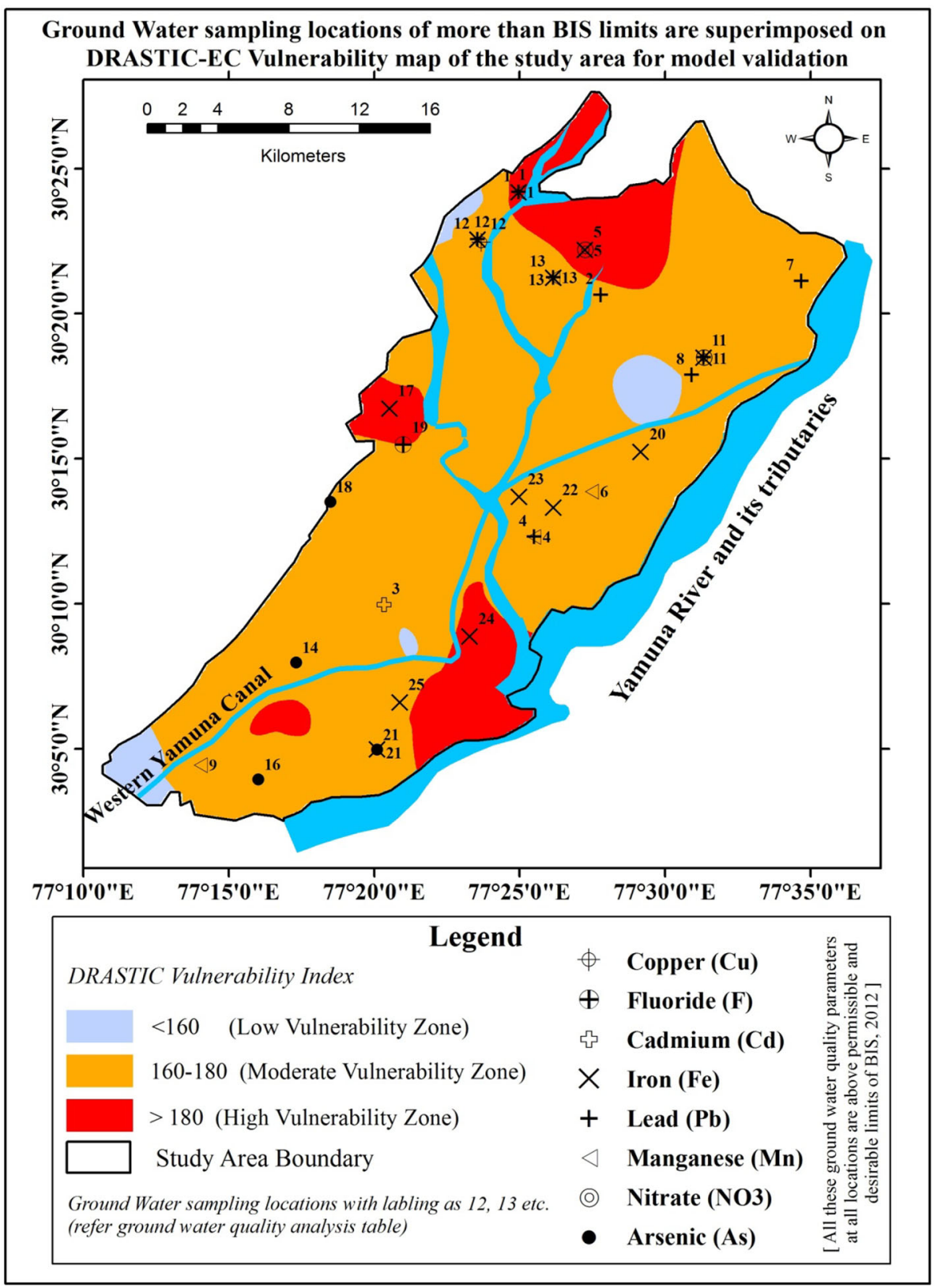

Figure 15. Superposition of ground water sampling locations (showing quality problems) on the DRASTIC-EC vulnerability map.

problem areas where ground water quality deterioration really occurred, and how much this GIS-based study helped in identifying them in the field. Eight parameters exceed the desirable limits prescribed by the BIS (2012). These eight locations are scattered in moderate to high vulnerability zones already identified by the GIS-DRASTIC-EC model. The model is thus validated with the fieldbased hydro-geochemical studies.

Besides the 25 locations in table 7 , there are five National Hydrograph Stations regularly monitored by CGWB in the study area (figure 16). Ground water samples for chemical analysis are collected from these stations once in a year. Historical chemical data (2007-2015) show that at Choli, $\mathrm{NO}_{3}$ concentrations display an increasing trend, and so does the ground water levels. While the rise in ground water levels could be due to greater reliance on surface water canals for irrigation purposes, higher levels of $\mathrm{NO}_{3}$ could be due to poor sanitary conditions, seepage from waste dumps and excess use of fertilizers for agricultural practices (Kumar and Das 2007). The other two stations, Khizrabad and Chhachhrauli, also occasionally show higher concentrations of $\mathrm{NO}_{3}$; the reasons could be similar to those of Choli. 


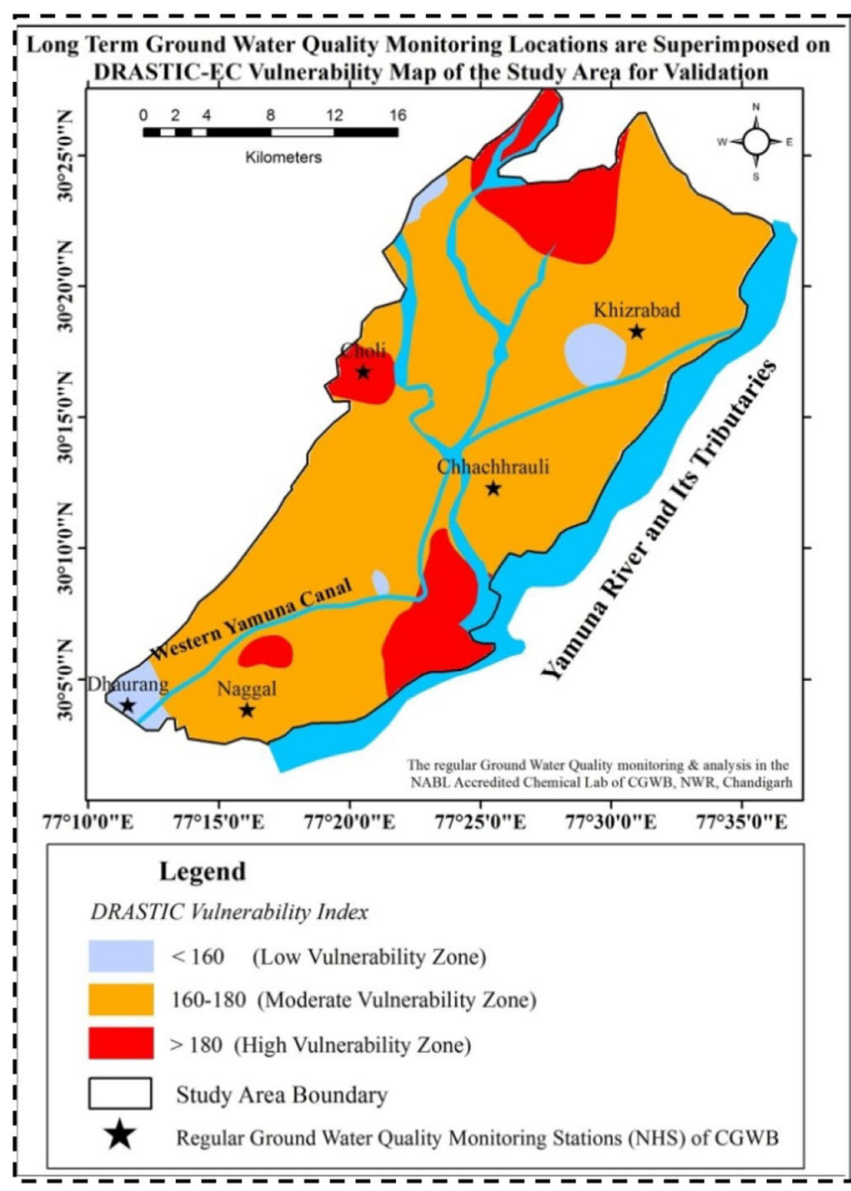

\section{Ground Water Quality parameters data (mg/lt) represented in sub-divided multiple bars}

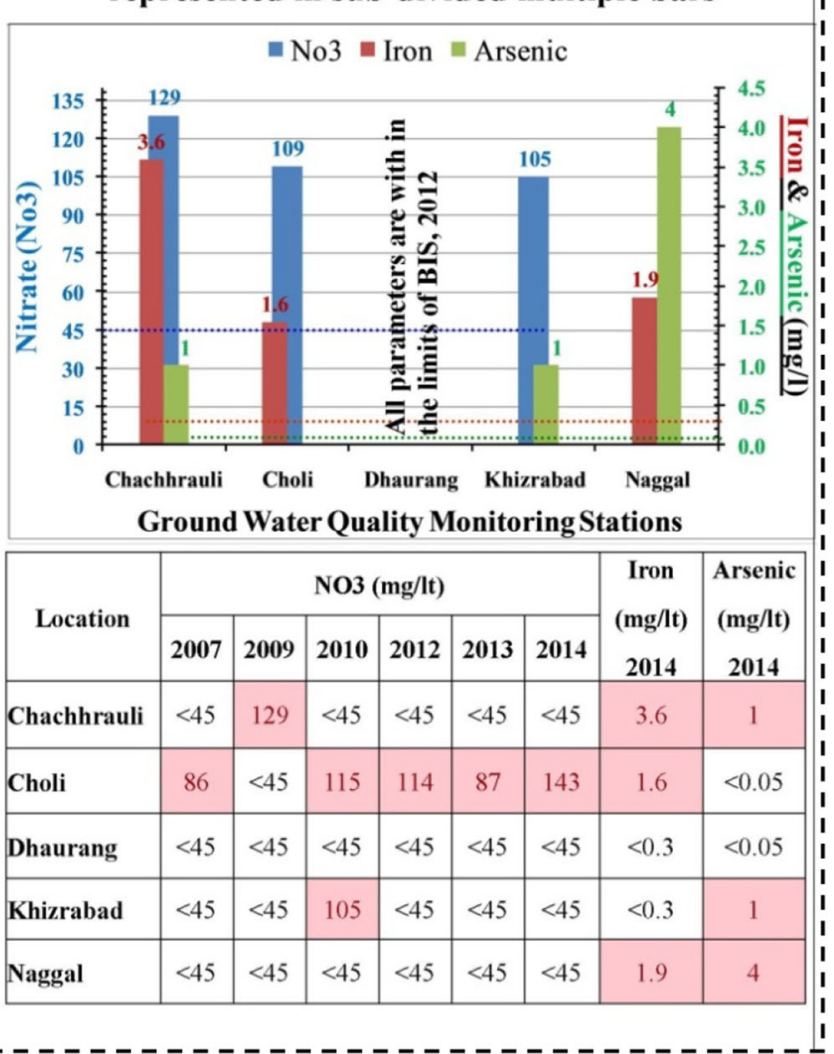

Figure 16. Historical ground water quality data analysis of the study area and model validation.

Arsenic and iron too show their presence above the maximum permissible limits in four of the five stations. The sources could be few chemical, electro-planting, petroleum refining, paper and pulp industries located around these areas (Kumar and Das 2007; MSME-DI 2012). All these four stations are located in moderate vulnerability zone identified by the GIS-DRASTIC-EC model. Dhaurang is the only station that does not show any quality deterioration and is located in the low vulnerability zone. These analyses again validate the independent findings of the GIS-DRASTIC-EC model.

\section{Conclusions}

GIS-DRASTIC model identifies seven parameters, such as the depth to water level (D), net recharge (R), aquifer media (A), soil media (S), topography $(\mathrm{T})$, impact of vadose zone (I) and hydraulic conductivity (C), as the controlling agents to define vulnerability zones. But, inclusion of EC as the eighth parameter in the model makes it more robust and precise in identifying vulnerable zones. The conventional model thus could be named as GIS-DRASTIC-EC model. Each parameter depending on its role has been assigned certain rating and weight for the purpose. But application of this model in fresh water zone in an area of about $800 \mathrm{~km}^{2}$ in the upper Yamuna catchment in Yamuna Nagar District of Haryana State, India, in the foothills of the Siwalik Hill Ranges that form a part of the Lower Himalayas shows that sensitivity of these parameters is areaspecific. In the study area, only four parameters are statistically significant with $>95 \%$ of confidence level: Depth to water (D), net Recharge (R), Aquifer media (A) and Topography (T) in order of significance. Electrical conductivity (EC) too plays an important role, but misses the significance level only marginally. On the basis of the DRASTIC-EC indices at 27 monitoring stations, three vulnerability zones have been identified: low vulnerability zone (index value: <160), moderate vulnerability zone (index value: $160-180$ ) and high vulnerability zone (index value: $>180$ ) with an areal extent of $05 \%\left(37 \mathrm{~km}^{2}\right), 80 \%\left(639 \mathrm{~km}^{2}\right)$ and 
15\% $\left(124 \mathrm{~km}^{2}\right)$, respectively. These vulnerability zones have been validated with 25 sampling locations and five national hydrograph stations from where water samples were collected for analysis of basic parameters as well as heavy metals. Ninety percent of these samples fall in moderate vulnerability zone. High vulnerability zones are found in low lying areas where stream meets with shallow water levels; ground water flows are too directed to these areas. On the basis of general basic parameters alone, apparently the ground water in the foothill zones does not really give any impression that it is actually contaminated. The three identified zones form recharge areas for the regions in the south, and it is essential that ground water resources in these areas are free from contamination always. However, GIS-DRASTIC-EC model successfully identifies vulnerability zones, which have been verified by the single parameter sensitivity analysis as well as hydro-geochemical study.

Therefore, instead of promoting industrial activities in the foothill zones, administration rather should encourage agricultural/horticultural activities in these areas so as to retain their environmental sanctity. In case industrialization has to happen, such areas should be classified as per GIS-DRASTIC-EC model first and then suitable preventive measures, such as creation of public awareness, better land use planning, etc., should be taken so that future pollution menace could be mitigated. However, the fact that pollution sources in alluvial areas act as point-sources, the whole alluvial tract that way becomes vulnerable. Therefore, more number of monitoring stations should be selected in these areas to have a better handling on the chemical quality of ground water. Foothill zones, because of their sensitivity, ought to have special policy framework for management of the water resources.

\section{Acknowledgements}

We express sincere gratitude to Mr K B Biswas, Chairman, Central Ground Water Board (CGWB) for granting permission to publish this paper. Assistance received from Mrs. B P Singh and Mr. Rishi Raj from CGWB, North Western Region, Chandigarh for chemical analysis of ground water samples is gratefully acknowledged. Special thanks to colleague Dr Fakhre Alam for some of his useful suggestions. Thanks are due to Dr P Ganapathi Rao for his help in the textural analysis of soil.

\section{References}

Alam F, Rashid U, Shakeel A and Ahmad F D 2012 A new model (DRASTIC-LU) for evaluating ground water vulnerability in parts of central Ganga Plain, India; Arab. J. Geosci, https://doi.org/10.1007/s12517-012-0796-y.

Aller L, Bennett T, Lehr J H and Petty R J 1987 DRASTIC: A standardized system for evaluating ground water pollution potential using hydrogeologic settings, U.SEPA/600/2-87/035, June 1987, Robert S Kerr, Environmental Research Laboratory, Ada OK 74820.

APHA (American Public Health Association) 1992 Standard methods for the examination of water and wastewater; 16th edn, APHA, Washington, D.C.

BIS 2012 Indian standard drinking water-specification (2nd Revision) BIS (IS-10500, 2012), New Delhi.

Bhatnagar N C, Agashe R M and Mishra A K 1982 Subsurface mapping of aquifer system: Water balance study of Upper Yamuna Basin, Section: Hydrogeology; Technical report No. 2, Upper Yamuna Project: Central Ground Water Board, North Western Region, Chandigarh.

CGWB (Central Ground Water Board) 2014 Report on Dynamic Ground Water Resources of Haryana State as on March 2011; Central Ground Water Board, North Western Region, Chandigarh.

Chakraborty S and Sikdar P K 2007 Assessing aquifer vulnerability to arsenic pollution using DRASTIC and GIS of North Bengal Plain: A case study of English Bazar Block, Malda District, West Bengal, India; J. Spatial Hydrol. 7(1) 101-121.

CoI (Census of India) Haryana 2011 District Census Handbook-Yamuna Nagar, Village and Town Directorate, Directorate of Census Operations, Haryana, Series- 7 , Part-XII-A, Page. No. 12, http://www.censusindia. gov.in/2011census/dchb/DCHB_A/06/0603_PART_A_ DCHBYAMUNANAGAR.pdf.

CPCB (Central Pollution Control Board) 2013 Pollution Assessment: River Ganga. CPCB, Ministry of Environment and Forest, Govt. of India, 197p.

Gogu R C and Dassarguess A 2000 Current trends and future challenges in ground water vulnerability assessment using Overlay and index methods; Environ. Geol. 39(6) 549559.

GWREC (Ground Water Resources Estimation Committee) 1997 Report of ground water resource estimation committee; Ministry of Water Resources, Government of India, New Delhi.

Herojeet R, Rishi M S, Lata R and Sharma R 2016 Application of environ metrics statistical models and water quality index for ground water quality characterization of alluvial aquifer of Nalagarh Valley, Himachal Pradesh, India; Sustain. Water Resour. Manag. 2(1) 39-53, http://link. springer.com/article/10.1007/s40899-015-0039-y.

Hussain M H, Singhal D C, Joshi H and Kumar S 2006 Assessment of ground water vulnerability in tropical alluvial interfluves, India; Bhu-Jal News, Central Ground Water Resources, Ministry of Water Resources, 1-4 $31-43$.

Iqbal J, Gorai A K, Katpatal Y B and Pathak G 2014 Development of GIS-based fuzzy pattern recognition model 
(modified DRASTIC model) for ground water vulnerability to pollution assessment; Int. J. Environ. Sci. Technol, https://doi.org/10.1007/s13762-014-0693-x.

Kamaldeep, Rishi M S, Kochhar N and Ghosh N 2011 Impact of industrialization on ground water quality: A case study of Baddi-Barotiwala Indusrial belt, District Solan, Himachal Pradesh, India; J. Indust. Pollut. Control. 27(2) 153-159.

Khan M M A, Umar R and Lateh H 2010 Assessment of aquifer vulnerability in parts of Indo Gangetic plain, India; Inter. J. Phys. Sci. 5(11) 1711-1720, http://www. academicjournals.org/IJPS, ISSN 1992-1950 2010 Academic Journals.

Kumar Rakesh and Bhattacharya S 2008 To study heavy mineral suites and correlate the sedimentation patterns within Siwalik group of rocks in Ambala and Yamuna Nagar districts, Haryana, FS-2007-08, Petrology Division; Geol. Survey of India, Northern Region, Faridabad.

Kumar S and Das P 2007 Impact of effluents of Haryana distillery on groundwater quality in Yamunanagar city and surrounding areas, Haryana; Central Ground Water Board, North Western Region, Chandigarh.

Mendoza J A and Barmen G 2006 Assessment of ground water vulnerability in the Rio Artiguas basin, Nicaragna; Environ.Geol. 50 569-580.

MSME-DI (Micro, Small \& Medium Enterprises) - Development Institute 2012 Brief industrial profile of Yamunanagar District, Ministry of MSME, Govt. of India, 28p.

NBSS and LUP (National Bureau of Soil Survey and Land Use Planning) 1994 Soil Map of the Haryana State; Publications of National Bureau of Soil Survey and Land Use Planning (ICAR) and Department of Agriculture, Haryana State.

NRDWP-MDWS (National Rural Drinking Water Programme - Ministry of Drinking Water and Sanitation, Govt. of India) 2015 Village level water quality data; http://in diawater.gov.in/imisreports/Reports/WaterQuality/rpt_ WQM_ContaminationWiseLabTesting_S.aspx?Rep=0and $\mathrm{RP}=\mathrm{Y}$.

NRSC-ISRO (National Remote Sensing Centre - Indian Space Research Organization) 2008 Data accessed and downloaded for preparation of elevation map (Cartosat1 Data: C1_DEM_16b_2006-2008_V1_77E30N_H43L), http://bhuvan.nrsc.gov.in/data/download/index.php.

NRSC-ISRO (National Remote Sensing Centre - Indian Space Research Organization) 2012 Land Use Land Cover (1:50000 scale): 2011-12 data, http://bhuvan.nrsc.gov.in/ gis/thematic/index.php.

NRSC-GSI (National Remote Sensing Centre - Geological Survey of India) 2010 Manual for geomorphological and lineament mapping on 1:50000 scale; National Remote
Sensing Centre and Geological Survey of India combined Project.

Qinghai G, Yanxin W, Xubo G and Teng M 2007 A new model (DRARCH) for assessing ground water vulnerability to arsenic contamination at basin scale: A case study in Taiyuan basin, northern China; Environ. Geol. 52 923-932.

Rahman A 2008 A GIS based DRASTIC model for assessing ground water vulnerability in shallow aquifer in Aligarh, India; Appl. Geogr. 28 32-53, https://doi.org/10.1016/j. apgeog.2007.07.008.

Saha D and Fakhre Alam 2014 Ground water vulnerability assessment using DRASTIC and pesticide DRASTIC models in intense agriculture area of the Gangetic Plains, India; Environ. Monit. Assess. 186(12) 8741-8763.

Sarma V V J and Narayanaswamy A 1981 Groundwater quality in Vishakhapatnam basin, India; Water Air Soil Pollut. 16 317-329.

Singh A, Srivastav S K, Sudhir Kumar and Chakrapani G J 2015 A modified DRASTIC model (DRASTICA) for assessment of ground water vulnerability to pollution in an urbanised environment in Lucknow, India; Environ. Earth Sci. 74 5475-5490, https://doi.org/10.1007/ s12665-015-4558-5.

Thiessen A H 1908 Thiessen polygons definition; https:// en.wikipedia.org/wiki/Voronoi_diagram and https://en. wikipedia.org/wiki/Alfred_H._Thiessen.

Todd D K and Mays L W 2015 Ground water hydrology, 3rd edn, Wiley, pp. 36-37.

Thomas Liz 2017 How to convert TDS to conductivity; Sciencing dated April 24, 2017, http://sciencing.com/ convert-tds-conductivity-7381015.html.

Umar R, Ahmed I and Alam F 2009 Mapping ground water vulnerable zones using modified DRASTIC approach of an alluvial aquifer in parts of central Ganga Plain, western Uttar Pradesh; J. Geol. Soc. India 73 193-201.

Verma B C 1976 Geological mapping and systematic collection of vertebrate fossils and stone artefacts from the Upper Siwalik Formation and Yamuna river terraces of Solan and Sirmur districts of HP and Rupar district of Punjab; Unpublished Report; Geological Survey of India, (F.S: 1974-75).

Vias J M, Andreo B, Perles M J and Carrasco F 2005 A comparative study of four schemes for ground water vulnerability mapping in a diffuse flow carbonate aquifer under Mediterranean climatic conditions; Environ. Geol. $47586-595$.

Vrba J and Zaporozec A 1994 Guidebook on Mapping Ground water Vulnerability; IAH International Contributions to Hydrogeology FRG, Heise Publication, Hannover 16 131p. 